\title{
Monoclonal Antibodies Distinguish Several Differentially Phosphorylated States of the Two Largest Rat Neurofilament Subunits (NF-H and NF-M) and Demonstrate Their Existence in the Normal Nervous System of Adult Rats
}

\author{
Virginia M.-Y. Lee, Martin J. Carden, William W. Schlaepfer, and John Q. Trojanowski \\ The Division of Neuropathology, Department of Pathology and Laboratory Medicine, University of Pennsylvania Medical \\ School, Philadelphia, Pennsylvania 19104
}

A new panel of $>\mathbf{3 0 0}$ monoclonal antibodies (mAbs) was prepared to the high, middle, and low $M_{\mathrm{r}}$ rat neurofilament (NF) subunlts (NF-H, NF-M and NF-L, respectively). NF proteins were purified both from native, i.e., phosphorylated rat NFs and from enzymatically dephosphorylated rat NFs. The resulting mAbs were used to biochemically and immunochemically distinguish and characterize distinct and differentially phosphorylated isoforms of NF subunits. By immunoblot, all mAbs specific for NF-L and some mAbs specific for NF-M detected their specific NF subunit regardless of whether or not the NFs had been treated with alkaline phosphatase, and such antibodies were termed "phosphate-independent" or P[ind] mAbs. The other mAbs were specific for NF-M, NF-H, or for both NF-M and NF-H, and they recognized epitopes in the $\mathrm{COOH}$ termini of these subunits. Significantly, the latter mAbs could discriminate different isoforms of NF-M and NF-H, depending on the phosphorylation state of each variant. Such mAbs were assigned to one of 4 distinct categories on the basis of their performance in immunoblots of progressively dephosphorylated rat NF samples and by immunohistochemistry of various adult rat nervous tissues: (1) PI-] mAbs preferentially stained neuronal perikarya and dendrites, and they recognized only extensively dephosphorylated (and nonphosphorylated) NF-H; (2) $\mathrm{P}[+] \mathrm{mAbs}$ stained axons more strongly than perikarya, and primarily blotted phosphorylated, but not nonphosphorylated, forms of NF-H and NF-M; (3) P ++$]$ mAbs stained axons almost to the exclusion of perikarya, and in blots recognized only the extensively phosphorylated forms of NF-H and NF-M (i.e., subunits subjected to limited enzymatic dephosphorylation); (4) P[ +++$]$ mAbs also predominantly stained axons, but the briefest alkaline phosphatase treatment abolished the NF-M and NF-H immunobands produced by these mAbs. Two-dimensional gel analysis and immunoblotting of

\footnotetext{
Received Jan. 20, 1987; revised May 8, 1987; accepted May 14, 1987.

This work was supported by a Postdoctoral Fellowship (M.J.C.) from the National ALS Foundation of America and by NIH Grants CA-36245 (J.Q.T.), NS15722 (W.W.S.), NS-18616 (V.M.-Y.L.), and PO-AG-06107. Grateful thanks are expressed to Mr. E. Clark, Ms. J. Ho, Mr. M. Memmo, Ms. C. Page, and Ms. T. Schuck for assistance with all aspects of this work.

Correspondence should be addressed to Virginia M.-Y. Lee, Division of Neuropathology, Department of Pathology and Laboratory Medicine, 449 Johnson Pavilion, University of Pennsylvania School of Medicine, Philadelphia, PA 191046079 .

Copyright (C) 1987 Society for Neuroscience $0270-6474 / 87 / 113474-15 \$ 02.00 / 0$
}

total proteins from adult rat dorsal root ganglion verified $\mathrm{mAb}$ specificity in situ, and showed that differentially phosphorylated isoforms of NF-M and NF-H occur in vivo. This provided additional evidence that mAbs can detect all 4 phosphorylation-dependent endogenous isoelectric variants of NF-H and NF-M. Notably, the effects of progressive phosphate addition to NF-M or NF-H appear additive by immunological criteria, such that $P[+]$-type mAbs, for example, recognize unique, poorly phosphorylated variants of NF-M and NF-H, in addition to the more extensively phosphorylated ones that are recognized by $\mathrm{P}[++]$ - and $\mathrm{P}[+++]$-type mAbs.

We conclude that multiple isoforms of NF-H and NF-M result from their differential phosphorylation at $\mathrm{COOH}-\mathrm{O}$-rminal sites, that these variants can be identified with mAbs, and that they can be demonstrated in situ by immunocytochemistry and in immunoblots. Since the delineation of a variety of biochemically distinct NF-H and NF-M isoforms by mAbs could be correlated predictably with the staining patterns produced by the mAbs in tissue, these mAbs are useful reagents for probing the functional and pathological implications of NF protein phosphorylation, and for monitoring activities of NF-directed protein kinase(s) and phosphatase(s). Last, we suggest that NF phosphorylation is not an exclusively axonal event and that axon-specific immunostaining in normal neurons by certain types of anti-NF mAbs may reflect the recognition of only the most extensively phosphorylated state of NF proteins.

Mammalian neurofilaments (NFs), the intermediate filaments of neurons, are composed of 3 different polypeptides, commonly referred to as the high (NF-H), middle (NF-M), and low (NFL) $M_{\mathrm{r}}$ subunits (Liem et al., 1978; Schlaepfer and Freeman, 1978). Each subunit is a separate gene product (Czosnek et al., 1980) and the genes for mouse NF-L (Lewis and Cowan, 1985, 1986) and human NF-M (Myers et al., 1987) have now been cloned. Despite their origin in different genes, all of the NF subunits contain alpha-helical, coiled-coil "core" domains that are highly homologous to one another at the amino acid sequence level. Similar domains, also homologous at the primary structural level, exist in the 20-30 polypeptide subunits that comprise the various other classes of intermediate filaments present in non-neuronal cells (e.g., Steinert et al., 1985; Traub, 1985). The greater mass of NF-H and NF-M, compared to that of NF-L and all other intermediate filament subunits, is due to 
long extensions of sequence on the $\mathrm{COOH}$-terminal side of the conserved core domain (Geisler et al., 1983; Myers et al., 1987). These long $\mathrm{COOH}$ termini can be removed almost intact by brief tryptic proteolysis, yet the filamentous structure of the NFs remains intact (Chin et al., 1983).

All 3 NF polypeptides are phosphorylated in vivo, but this occurs in proportion to the mass of each subunit, such that NF-H is the most extensively phosphorylated, NF-L the least phosphorylated, and NF-M is intermediate between NF-H and NF-L in its phosphate content (e.g., Julien and Mushynski, 1982; Carden et al., 1985). The extent of NF-H and NF-M phosphorylation determines important biochemical properties of these subunits. For example, following enzymatic dephosphorylation, NF-H and NF-M migrate faster by SDS-PAGE (e.g., Julien and Mushynski, 1982; Carden et al., 1985; Glicksman and Willard, 1985; Kaspi and Mushynski, 1985; Lee et al., 1986b; Schmidt et al., 1987). Further, the phosphorylation state of NF-H and NF-M is a significant determinant of their immunological properties (Goldstein et al., 1983, 1987; Sternberger and Sternberger, 1983; Carden et al., 1985; Lee et al., 1986a, b; Shaw et al., 1986; Schmidt et al., 1987). Finally, phosphorylation sites are located on the peripheral, COOH-terminal portions of NF-H and NF-M (Julien and Mushynski, 1983; Geisler et al., 1985), such that the exterior of the filament is highly modified. Thus, phosphorylation may have a functional role in regulating the interaction between NFs and their surroundings.

Phosphorylated species of mammalian NF-H are the most immunogenic form of this subunit (Carden et al., 1985; Glicksman and Willard, 1985; Lee et al., 1986a, b; Shaw et al., 1986), and studies based on the use of antibodies raised to conventional NF immunogens may fail to detect nascent or unphosphorylated forms of NF-H (Lee et al., 1986b). Further, nascent forms of mammalian NF-M have not been described and attention has not been directed at examining whether immunologically distinct variants, or isoforms, of mammalian NF-M and NF-H are generated during the progressive addition of phosphate groups to these NF subunits by neuronal kinase(s). We report here a new library of mAbs that can distinguish differentially phosphorylated (or enzymatically dephosphorylated) isoforms of NF-H and NF-M. Further, we also show that each of these differentially phosphorylated isoforms of rat NF-H and NF-M exists normally in situ. The following report (Carden et al., 1987) provides additional support for this observation; we show that some of these isoforms are expressed asynchronously in neurons during the development of the rat CNS and PNS.

\section{Materials and Methods}

Purification of rat neurofilaments. The method used here was adapted from previous protocols (Schlaepfer and Freeman, 1978; Carden and Eagles, 1983; Carden et al., 1985). Twenty adult (ca. $250 \mathrm{gm}$ ), deeply anesthetized Sprague-Dawley rats were perfused with ice-cold PBS (10 mM Na $2 \mathrm{HPO}_{4} / \mathrm{NaH}_{2} \mathrm{PO}_{4}, 150 \mathrm{~mm} \mathrm{NaCl}, \mathrm{pH} 7.3$ ) containing 2 mM EGTA. Spinal cords were excised, separated from their dural sheath, weighed (ca. $1 \mathrm{gm}$ each), chopped into $2 \mathrm{~mm}$ segments, and immersed for $1 \mathrm{hr}$ at $4^{\circ} \mathrm{C}$ in $500 \mathrm{ml}$ of ice-cold hypotonic buffer $(10 \mathrm{~mm}$ Tris- $\mathrm{HCl}, 2 \mathrm{~mm}$ EGTA, $1 \mathrm{~mm}$ dithiothreitol, and $50 \mathrm{~mm} \mathrm{NaCl}, \mathrm{pH} \mathrm{7.0)}$. About $2 \mathrm{hr}$ were needed to complete these steps, and all subsequent procedures were performed at $4^{\circ} \mathrm{C}$. Swollen tissues were homogenized in a glass/ glass Potter-Elvenjhem type tissue grinder using $1.5 \mathrm{ml}$ of isotonic buffer per gram of tissue. Isotonic buffer was identical to hypotonic buffer except that $\mathrm{NaCl}$ was present at a concentration of $150 \mathrm{~mm}$. The homogenate was centrifuged at $5000 \times g$ for $5 \min \left(4^{\circ} \mathrm{C}\right)$ to yield a loose pellet. The supernatant (first extract) was decanted and saved on ice. The pellet was resuspended in a volume of isotonic buffer equaling that of the first extract. Further NFs were released by agitating the mixture

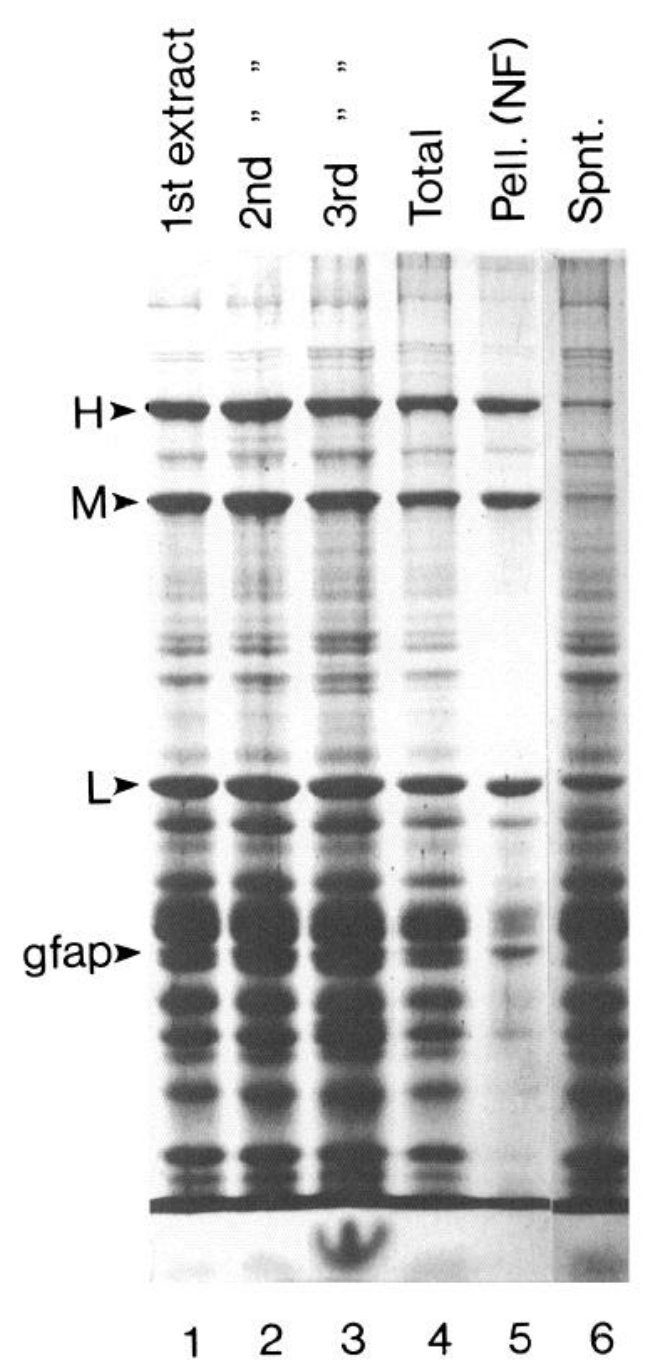

Figure 1. SDS-PAGE (7.5\% polyacrylamide) of samples taken during the isolation of NFs from rat spinal cord. The $3 \mathrm{NF}$ polypeptide subunits are marked $(H, M$, and $L)$, as is the position of the glial filament subunit (gfap).

using a Polytron tissue disrupter (Brinkmann Instruments) for $1 \mathrm{~min}$ at low speed (ca. 2-5). This homogenate was centrifuged as before, and the supernatant (second extract) was combined with the first extract. A third extraction step was performed exactly as for the second, except that the Polytron was operated at top speed for $2 \mathrm{~min}$. The combined extracts $(1-3)$ were made up to $0.85 \mathrm{M}$ sucrose using $1.5 \mathrm{M}$ sucrose in isotonic buffer. This NF-rich suspension was centrifuged overnight (14$18 \mathrm{hr}$ ) at $100,000 \times \mathrm{g}, 4^{\circ} \mathrm{C}$. The resulting NF pellets were suspended at about $5 \mathrm{mg} / \mathrm{ml}$ by homogenization in isotonic buffer and used immediately or stored at $-70^{\circ} \mathrm{C}$ after adding glycerol at $20 \%$.

Figure 1 shows the SDS-PAGE profile of protein composition in samples taken at various stages during the purification of rat NFs by the new method. Extraction of the spinal cord was halted after the third cycle because the number non-NF protein contaminants began to increase (Fig. 1, lanes 1-3). The major contaminant, glial fibrillary acidic protein (gfap), cosedimented with NFs (lane 5). Contaminants and presumed NF degradation products were noticed by SDS-PAGE (not shown) when the perfusion step was omitted. From 20 rat spinal cords, the method yielded $20-50 \mathrm{mg}$ of NF proteins of $>80 \%$ purity, as judged by SDS-PAGE (Fig. 1, lane 5) and these were clear and gelatinous, as described previously for bovine NFs isolated from nerve roots (Carden and Eagles, 1983). In contrast, Triton-containing buffers produced smaller, more opaque NF pellets, and SDS-PAGE of lipid pads seen in the last centrifugal step (not shown) revealed that the decreased yield in Triton buffers was due to the enhanced association of NF proteins with lipids (see also Traub et al., 1986). 
Figure 2. SDS-PAGE (7.5\% polyacrylamide) demonstrates the effect of dephosphorylation by $E$. coli alkaline phosphatase upon the mobilities of NF-M and NF-H. Incubation times are indicated above each lane. Phosphate buffer was added to the sample in lane 8 to inhibit dephosphorylation; otherwise, the phosphate inhibited $(P I)$ sample was treated identically to the one in lane 7 . Note the resolution of NF-M into 3 bands in lane 3.

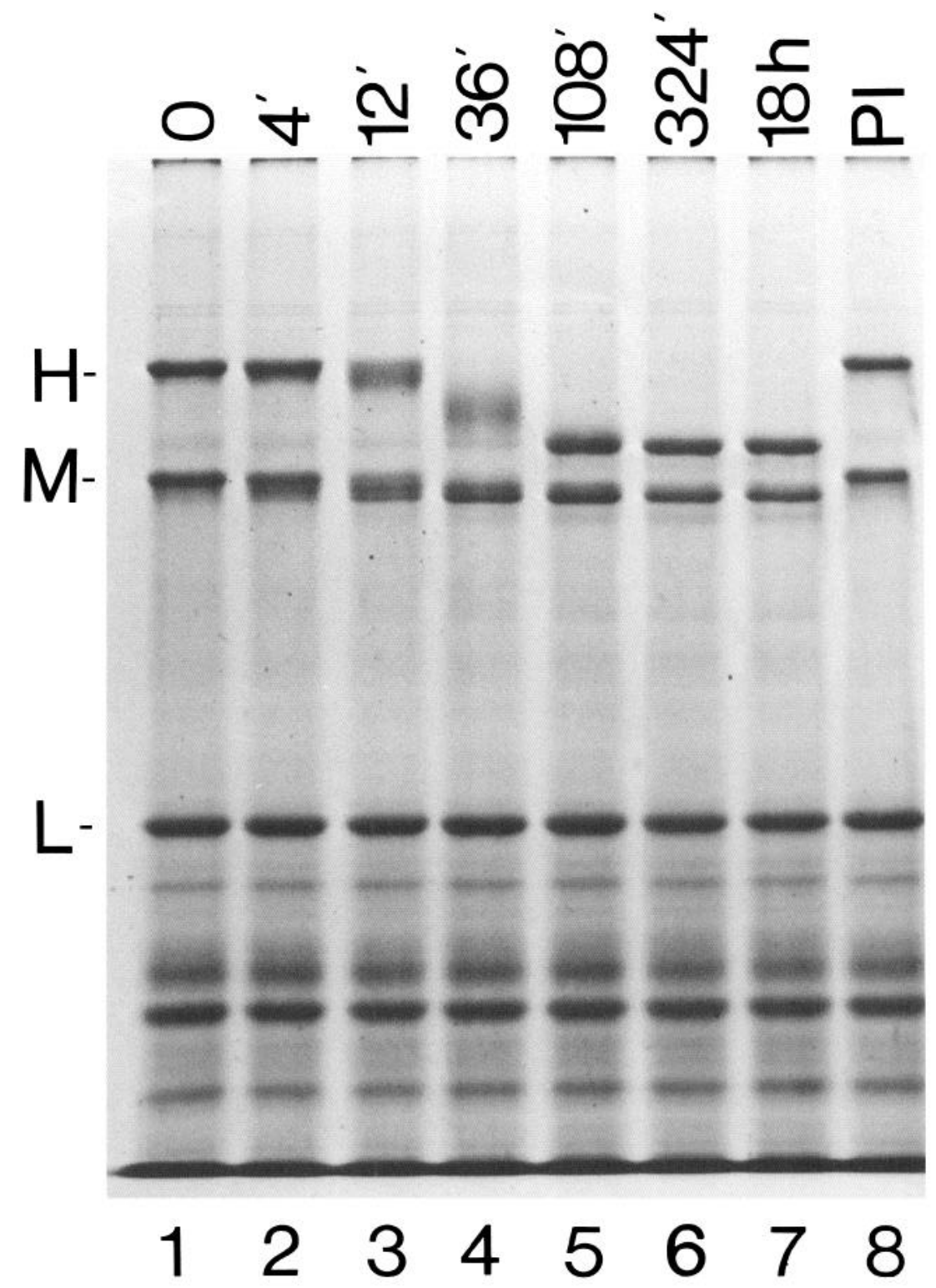

Enzymatic dephosphorylation of rat neurofilaments. Rat NF preparations were dephosphorylated either in solution or in nitrocellulose replicas of SDS-PAGE gels, as described previously (Carden et al., 1985). Briefly, NFs $(1-5 \mathrm{mg} / \mathrm{ml})$ in buffer $(50 \mathrm{~mm}$ Tris- $\mathrm{HCl}, 100 \mathrm{~mm}$ $\mathrm{NaCl}, 1 \mathrm{~mm} \mathrm{ZnSO}$, pH 8.0) were mixed with 2-20 units of $E$. coli alkaline phosphatase (type III-N; Sigma Chemicals) per milligram of protein, and incubated for $18 \mathrm{hr}$ at $37^{\circ} \mathrm{C}$. Shorter times $(4 \mathrm{~min}$ to $5 \mathrm{hr}$ ) yielded less extensively dephosphorylated NFs. Dephosphorylation was stopped by the addition of an equal volume of inhibition buffer $(400$ mм Na $\mathrm{HPO}_{4} / \mathrm{NaH}_{2} \mathrm{PO}_{4}, 50$ m 5 ETA, $100 \mathrm{~mm} \mathrm{NaCl}$, pH 7.0). Centrifugation at $100,000 \times g\left(r_{\mathrm{av}}=7 \mathrm{~cm}\right)$ pelleted the NFs free from $>90 \%$ of the phosphatase. Supernatants were free of NF proteins.

Figure 2 shows SDS-PAGE analysis of a typical dephosphorylation experiment. NF-H and NF-M migrated further in the gels after longer incubations of NFs with phosphatase in solution (Fig. 2, lanes 1-7). This shift in $M_{\mathrm{r}}$ stabilized after $108 \mathrm{~min}$ of enzyme treatment. Similar data in other species have been reported (Julien and Mushynski, 1982; Carden et al., 1985; Glicksman and Willard, 1985; Kaspi and Mushynski, 1985; Lee et al., 1986b; Schmidt et al., 1987). During dephosphorylation of rat NFs, NF-M was resolved into 3 distinct bands (e.g., Fig. 2, lane 3), which we designate NF-Ma, NF-Mb, and NF-Mc in order of their increasing migration and, presumably, their diminishing phosphate content. These same products, which we call isoforms, are apparent in the starting NFs (Fig. 2, lane 1), but NF-Ma is by far the most abundant species. Small amounts of the most dephosphorylated form of NF-H are also evident prior to the enzymatic dephosphorylation of NF proteins (Fig. 2, lane 1). As discussed earlier (Carden et al., 1985; Georges et al., 1986; Ksiezak-Reding and Yen, 1986; Lee et al., 1986b), changes in the $M_{\mathrm{r}}$ of NF proteins in SDS-PAGE gels do not necessarily correlate quantitatively with the number of removed phosphates, and enzyme-treated rat NFs may be extensively, but not necessarily completely, dephosphorylated by this enzyme.

Chymotryptic digestion of rat neurofilaments. NFs $(1-5 \mathrm{mg} / \mathrm{ml}$ in 50 $\mathrm{mm}$ Tris- $\mathrm{HCl}, 150 \mathrm{~mm} \mathrm{NaCl}, 1 \mathrm{~mm}$ dithiothreitol, $\mathrm{pH}$ 7.3) were digested for different amounts of time with alpha-chymotrypsin (DPCC-treated; Sigma) at $0.04-25 \mu \mathrm{g} / \mathrm{ml}$. A 100 -fold excess of phenylmethyl sulfonyl fluoride (PMSF) was added to terminate the reaction, and the sample was immediately centrifuged at top speed in a Beckman Airfuge for 1$5 \mathrm{hr}$ at $20^{\circ} \mathrm{C}$. The pellets and supernatants were separated, suspended in SDS-PAGE sample buffer, heated, and immediately separated on gels.

Figure 3 shows the SDS-PAGE profile of NF proteins treated for 1 $\mathrm{hr}$ with different amounts of chymotrypsin. At low concentration of this protease, the bulk of the NF proteins still sedimented (Fig. 3, lane 1), although new bands at apparent $M_{\mathrm{r}} \mathrm{s}$ of 160,000 and 120,000 were released into the supernatant (Fig. 3, lane $1^{\prime}$ ). These represented the $\mathrm{COOH}$-terminal, peripheral domains of NF-H and NF-M, respectively (see Julien and Mushynski, 1983, and Results). The release of these 
bands was accompanied by the appearance in the pellet fraction of core fragments having $M_{\mathrm{r}} 40-60,000$ (Fig. 3, lane 1). Higher concentrations of chymotrypsin released more of the soluble fragments and also converted them into slightly smaller products, with apparent $M_{\mathrm{r}} \mathrm{s}$ of 150,000 and 110,000 (Fig. 3, lane $5^{\prime}$ ). Extensive chymotryptic digestion rendered the bulk of the proteins soluble, including large amounts of the core fragments. Note that the $M_{\mathrm{r}} 120,000$ band (derived from NF-M) partitions with the pelleted fraction as well as with the supernatant, whereas the smaller $\left(M_{\mathrm{r}} 110,000\right)$ fragment of the same protein is almost completely soluble. For the characterization of $\mathrm{mAbs}$ against core versus peripheral domains, preparations similar to that in lane 3 ' of Figure 3 were used for immunoblot analyses.

One- and two-dimension SDS-PAGE methods. One-dimension analysis of protein was performed with 0.75 -mm-thick, $7.5 \%$ polyacrylamide gels, or 5-15\% gradient gels. Preparative SDS-PAGE separation of proteins was performed in 3-mm-thick, $7.5 \%$ polyacrylamide gels. Enzymatically dephosphorylated NF proteins were separated using 6\% polyacrylamide gels. All of these procedures have been published (Carden et al., 1985; Lee et al., 1986a, b; Schmidt et al., 1987). Protein was eluted from gel slices by diffusion in ultrapure deionized water, and the fractions were monitored by SDS-PAGE, combined as appropriate. They were then dialyzed against water, lyophilized, resuspended in a minimum volume of water, dialyzed again, lyophilized again, and used or stored at $-70^{\circ} \mathrm{C}$.

Two-dimension gels involved separation of urea-denatured proteins by IEF or nonequilibrium $\mathrm{pH}$ gradient electrophoresis (NEPHGE) in the first dimension, followed by SDS-PAGE in the second. NEPHGE and IEF were conducted as described earlier (Lee et al., 1986b) using $\mathrm{pH}$ gradients of 4.5-8.0 for IEF, and 4.0-9.0 for NEPHGE, generated with LKB ampholines ( $\mathrm{pH} 3.5-10, \mathrm{pH} 5-7$, and $\mathrm{pH} 4-6$ mixed in a ratio of 2:9:9 for IEF and $\mathrm{pH} 3.5-10$ for NEPHGE, all at a final total concentration of $2 \%$ ).

Generation and screening of antibodies. Antisera and mAbs were generated, and screened as previously described (Lee et al., 1982, 1984, 1986b). Adult Balb/c mice were immunized with the following gelpurified rat antigens: (1) NF-L (RMS mAbs); (2) untreated NF-M (RMO mAbs); (3) enzymatically dephosphorylated rat NF-M (RMdO mAbs); and (4) enzymatically dephosphorylated rat NF-H (RMdT mAbs). Initial hybridoma screening by ELISA (Lee et al., 1984, 1986b) was conducted with the following rat NF preparations: (1) NF-L; (2) untreated (phosphorylated) NF-H; (3) enzymatically dephosphorylated NF-H; (4) native NF-M; and (5) dephosphorylated NF-M. Subsequently, positive hybridomas were evaluated further in immunoblots (see below) that contained native rat NFs, and in immunoblots of gel replicas containing NFs that were enzymatically dephosphorylated on nitrocellulose paper (Lee et al., 1986b; and see below). Immunoblotting of pelleted and supernatant fractions from limited chymotryptic digestion of rat NFs (see above) was performed to indicate epitope location in filamentassociated (core) or peripheral portions of each NF protein. Finally, antibodies were screened by immunohistochemistry (see below) on adult rat spinal cord, dorsal root ganglia (DRG), and cerebellum. Selected mAbs were also characterized in immunoblots of NF proteins from DRGs separated using 2-dimensional gels.

Immunoblot methods. Transfer of proteins from SDS gels to nitrocellulose replicas, and the detection of antigens in these gel replicas with $\mathrm{mAbs}$ by an indirect immunoperoxidase or by a peroxidase-antiperoxidase (PAP) method were conducted as detailed earlier (Lee et al., 1984, $1986 \mathrm{a}, \mathrm{b})$. The mouse PAP complex $(1: 40,000)$ used here was prepared
Pellets
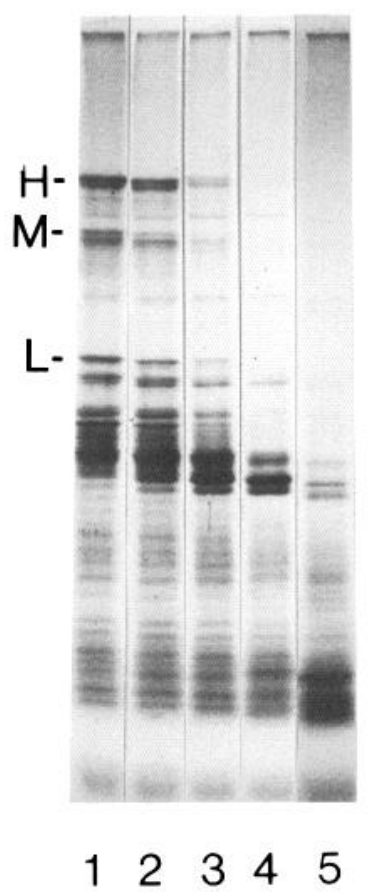

\section{Supernatants}
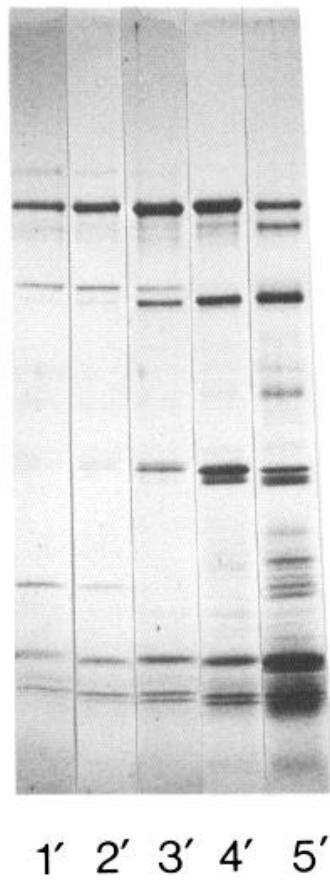

Figure 3. SDS-PAGE (5-15\% polyacrylamide gradient) of pelleted (lanes 1-5) and soluble (lanes $1^{\prime}-5^{\prime}$ ) products generated after digestion of rat NFs for $1 \mathrm{hr}$ with different amounts of chymotrypsin. Lane 1, $0.04 \mu \mathrm{g} / \mathrm{ml}$; lane 2, $0.2 \mu \mathrm{g} / \mathrm{ml}$; lane 3, $1.0 \mu \mathrm{g} / \mathrm{ml}$; lane $4,5 \mu \mathrm{g} / \mathrm{ml}$; lane $5,25 \mu \mathrm{g} / \mathrm{ml}$.

by Lee et al. (unpublished observations) with $\mathrm{mAbs}$ raised to horseradish peroxidase.

Immunohistochemistry. All of the mAbs were used to probe adult rat CNS and PNS tissues using the avidin-biotin complex (ABC) procedure on Bouin's fixed, paraffin-embedded tissues, and by immunofluorescence methods on frozen sections. These procedures and methods of data analysis have been published in detail (Hickey et al., 1983; Trojanowski et al., 1985, 1986; Lee et al., 1986b; Goldstein et al., 1987; Schmidt et al., 1987).

\section{Results}

Production and initial screening of NF-specific monoclonal antibodies

By ELISA screening, the 4 fusions described here yielded $31 \mathrm{NF}$ protein-positive clones from the NF-L fusion, 315 from the

Table 1. Subunit specificities of mAbs generated in each fusion

\begin{tabular}{llrrlrll} 
& NF-L & NF-M & NF-H & $\begin{array}{l}\text { NF-L/ } \\
\text { NF-M }\end{array}$ & $\begin{array}{c}\text { NF-M/ } \\
\text { NF-H }\end{array}$ & dpNF-H & $\begin{array}{l}\text { dpNF-H/ } \\
\text { dpNF-M }\end{array}$ \\
\hline RMS & 8 & 2 & 0 & 2 & 0 & 0 & 0 \\
RMO & 0 & 161 & 16 & 8 & 101 & 5 & 4 \\
RMdO & 0 & 2 & 0 & 0 & 0 & 5 & 2 \\
RMdT & 0 & 0 & 0 & 0 & 0 & 1 & 0
\end{tabular}

At the top of each column, the phosphorylated or dephosphorylated (dp) NF subunits recognized by a given mAb are listed. The number in each column indicates how many mAbs generated by each of the 4 fusions were specific for a given NF subunit or combination of NF subunits. All mAbs in the same horizontal row were produced using the same rat NF immunogen, which is shown on the far left (RMS = NF-L immunogen; RMO = NF-M immunogen; RMdO = dephosphorylated NF-M immunogen; RMdT = dephosphorylated NF-H immunogen). 


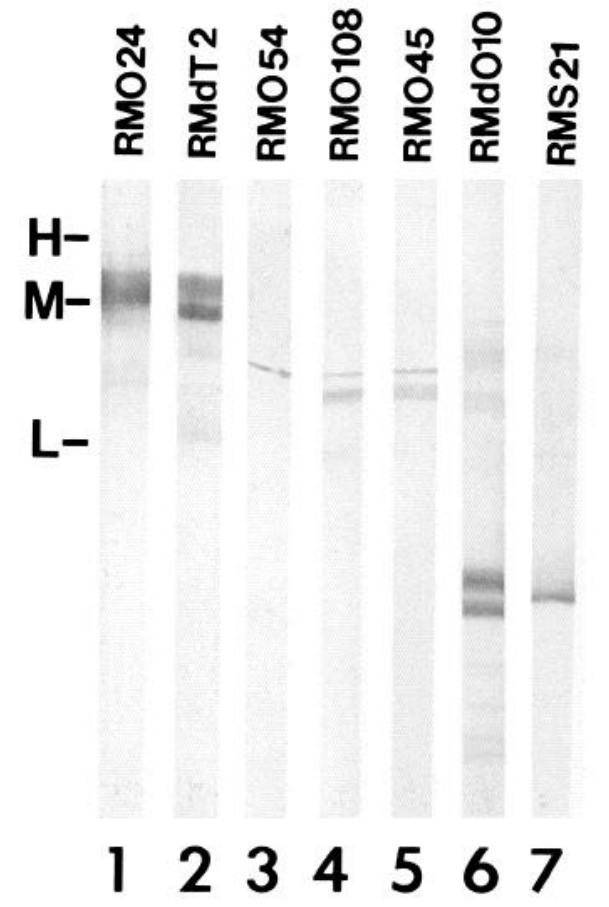

Figure 4. Immunoblots of chymotryptic fragments from rat NFs. Strips 1 and 2 were stained using NF-H-specific mAbs, 3-6 with mAbs to NF-M, and 7 with an NF-L-specific mAb. The positions of intact NF-H $(H)$, NF-M $(M)$, and NF-L $(L)$ are indicated on the left.

fusion using native NF-M, 21 from the fusion with dephosphorylated NF-M, and 12 from the dephosphorylated NF-H fusion. Only those mAbs that produced immunobands corresponding to authentic NF proteins in immunoblots were studied further. It is noteworthy that the immunogen used in a given fusion did not necessarily determine the specificity of the resulting mAbs. A large number of these new mAbs recognized epitopes shared by NF-M and NF-H, as was noted with mAbs to bovine and human NF (Carden et al., 1985; Lee et al., 1986a, Schmidt et al., 1987). Table 1 summarizes the subunit specificities of the mAbs generated in each of the fusions.

\section{Approximate location of $N F$ protein epitopes detected with these $m A b s$}

Figure 4 shows examples of the reaction patterns produced when the new mAbs were applied to nitrocellulose strips containing chymotryptic digests of rat NFs. NF-H-specific mAbs (Fig. 4, lanes 1 and 2) stained bands of apparent $M_{\mathrm{r}}$ around 160,000, i.e., the peripheral domain of rat NF-H (Julien and Mushynski, 1983). No NF-H-specific mAbs stained "core" bands, ca. 40 kDa. Antibodies specific for NF-M (Fig. 4, lanes 3-6) yielded 3 different staining patterns: The majority stained both bands of the doublet at $M_{\mathrm{r}} 120,000$ and 110,000 (Fig. 4, lanes 4 and 5), i.e., peripheral domain fragments from rat NF-M (Julien and Mushynski, 1983). Dilution of these NF-M-specific mAbs, or of the antigen, resulted in staining of the lower band $(110 \mathrm{kDa})$ alone, perhaps reflecting quantitative differences in the amounts of the 2 fragments (Fig. 3, lane 3'). However, one mAb (RMO54) consistently stained only the upper band $\left(M_{\mathrm{r}} 120,000\right)$ in the doublet (Fig. 4, lane 3). The third type of immunoblot pattern for NF-M-specific mAbs is shown in lane 6 of Figure 4; it typifies core-specific mAbs. Similar $40 \mathrm{kDa}$ NF-M fragments, but not the 120 and $110 \mathrm{kDa}$ peripheral domain fragments, were de- tected (data not shown) using a mAb (termed anti-IFA) produced by Pruss et al. (1981). This mAb is known to bind an epitope localized at the $\mathrm{COOH}$-terminal end of the proteolytically stable coiled-coil domain of all 3 NF proteins, and, indeed, of all intermediate filament proteins (Geisler et al., 1983). The last $\mathrm{mAb}$ shown in Figure 4 (lane 7), specific for NF-L, recognized a $40 \mathrm{kDa}$ protein also detectable with the anti-IFA mAb.

\section{Many $m A$ bs recognize $N F-M$ and/or $N F-H$ in different phosphorylation states}

Many mAbs specific for NF-M and/or NF-H, distinguished phosphorylated forms of these proteins from enzymatically dephosphorylated ones, or vice versa, during the initial ELISA and immunoblot screenings. These mAbs were characterized further, using gel replicas of rat NF proteins subjected to progressively longer periods of enzymatic dephosphorylation, in order to determine if they recognized differentially phosphorylated forms of either protein. Results obtained with representative mAbs are shown in Figure 5. Figure $5 I$ is a gel replica stained for protein; it reveals the polypeptides present in the replicas used to test the mAbs.

$N F-H$-specific antibodies. Blots $A-D$ of Figure 5 illustrate the 4 different kinds of phosphate-dependent behavior of the NF$\mathrm{H}$-specific mAbs. RMO24 (Fig. $5 A$ ) recognizes only the most highly phosphorylated and the most slowly migrating $\left(M_{\mathrm{r}}\right.$ 200,000 ) isoforms of NF-H and is categorized as a $\mathrm{P}[+++]$ mAb. Ta51 (also known as 4.3F9), obtained from an earlier fusion using bovine NF immunogens (Lee et al., 1982), illustrates a quite different pattern of phosphate-dependent immunoreactivity for NF-H (Fig. $5 C$ ). This $\mathrm{AAb}$ behaves in a manner characteristic of a class of mAbs termed $\mathrm{P}[+]$; they detect NF-H isoforms with a lower $M_{\mathrm{r}}$ than those detected with RMO24. A $\mathrm{P}[+] \mathrm{mAb}$ is therefore one that detects isoforms of NF-H that contain far fewer phosphate residues than those detected by $\mathrm{P}[+++] \mathrm{mAbs}$. We also identified $\mathrm{mAbs}$ with properties intermediate between $\mathrm{P}[+]$ and $\mathrm{P}[+++]$ (e.g., RMO217 in Fig. $5 B)$, which we term $\mathrm{P}[++]$ anti-NF-H mAbs. It is evident from the data presented here that $\mathrm{P}[+], \mathrm{P}[++]$, and $\mathrm{P}[+++] \mathrm{mAbs}$ define at least 3 classes of NF-H isoforms that are characterized, respectively, by having increasing numbers of phosphorylated residues.

The fourth category of anti-NF-H mAb is exemplified by RMdO20 (Fig. 5D), which only detects the most extensively dephosphorylated and rapidly migrating isoforms of NF-H. These mAbs are termed $\mathrm{P}[-] \mathrm{mAbs}$, and they are similar to those raised earlier to bovine NF-H immunogens subjected to extensive enzymatic dephosphorylation (Lee et al., 1986a, b).

$\mathrm{P}[-], \mathrm{P}[+], \mathrm{P}[++]$, and $\mathrm{P}[+++]$ anti-NF-H mAbs also recognized different isoforms of NF-H on nitrocellulose replicas of 2-dimension gels containing adult rat DRG proteins. Representative data from these studies are shown in Figure 6. For example, the properties of a $\mathrm{P}[+++]$ anti-NF-H mAb (RMO24) are seen in Figure $6 \mathrm{~A}$. RMO24 produced the heaviest reaction product in a region (see arrowhead on the left) of the gel replica that corresponded to the most acidic region in identical 2-dimension gels of the same DRG preparation, which were stained with Coomassie blue (data not shown). This highly acidic region is the primary isoform of NF-H recognized by $\mathrm{P}[+++]$ antiNF-H mAbs (i.e., the most phosphorylated, highest $M_{r}$, and most acidic isoelectric point). The properties of a $\mathrm{P}[+]$ anti$\mathrm{NF}-\mathrm{H} \mathrm{mAb}(\mathrm{Ta} 51)$ are seen in Figure $6 B$. The heaviest reaction product is localized to a position that is slightly more basic than 


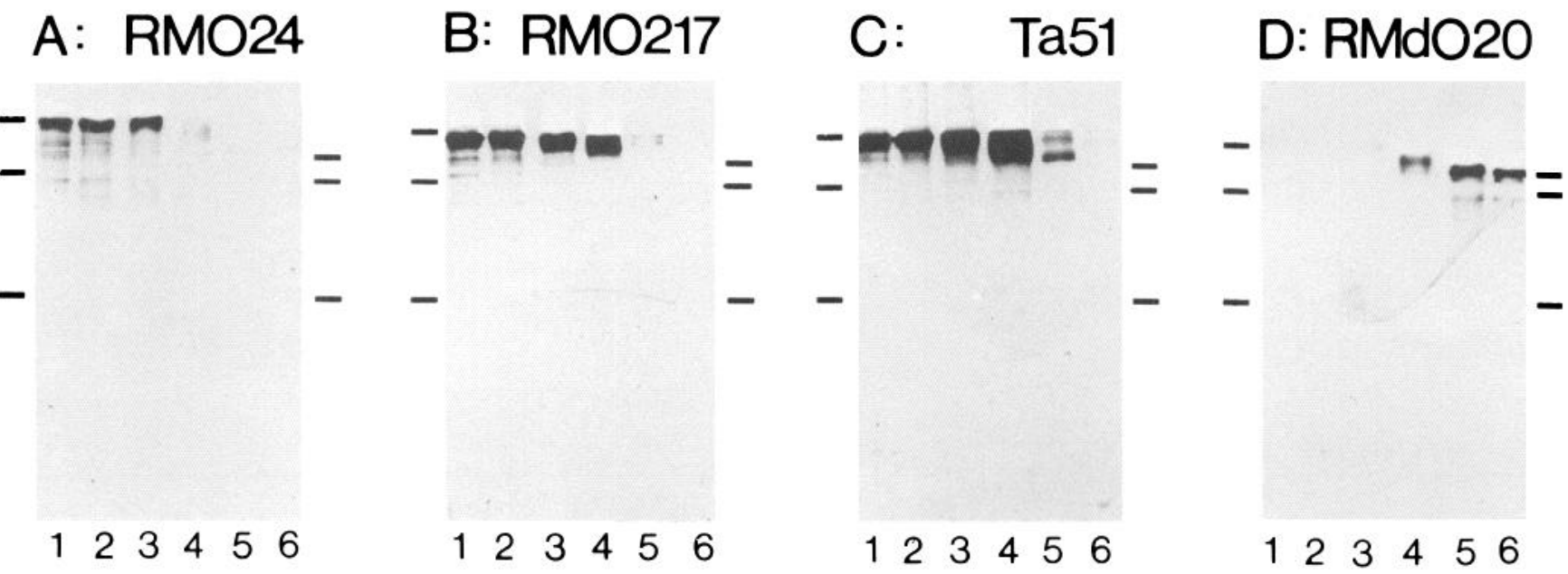

E. RMO45

F: RMdO10

G: RM0108

H: RMS21
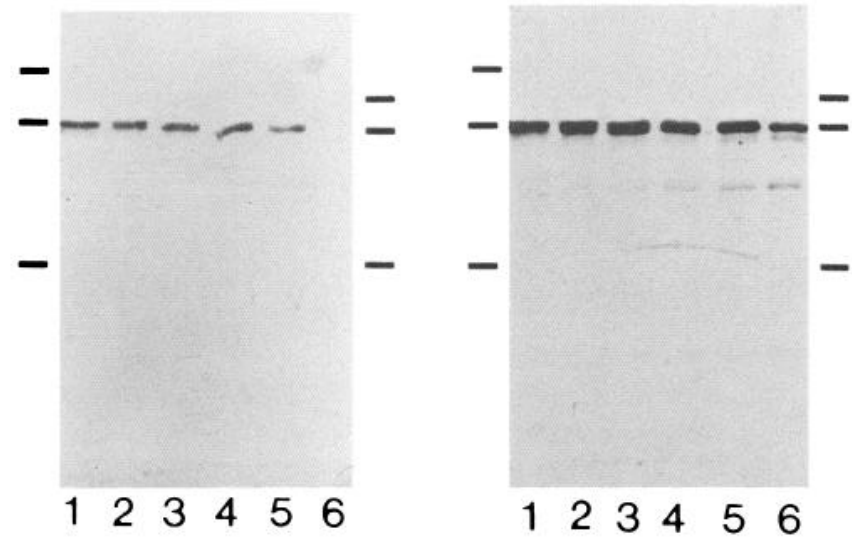

\section{(}




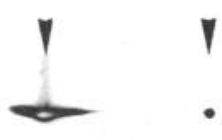

A

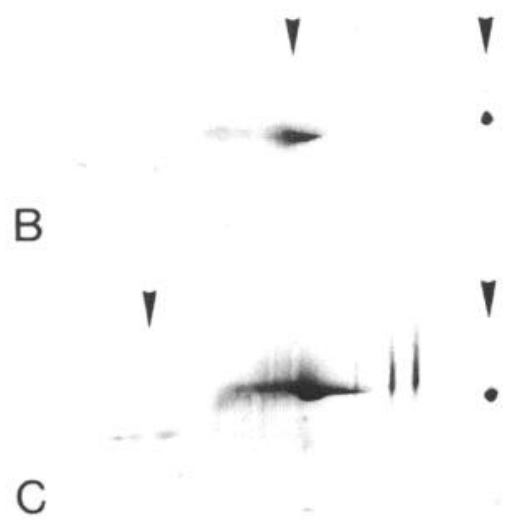

Figure 6. Immunoblots of DRG proteins separated in 2 dimensions by NEPHGE and SDS-PAGE and probed with different NF-H-specific mAbs. Each panel shows only the region containing immunoreactivity, i.e., the most acidic proteins of $M_{\mathrm{r}}$ around $200 \mathrm{kDa}$. Adult rat protein was separated in $A-C$, whereas in $D$ the DRG was from a young rat (postnatal day 4). The mAbs used were RMO24 $(A)$, Ta51 $(B)$, and RMdO9 $(C$ and $D)$. The spots indicated by the right-hand arrowheads in $A-C$ are immunoreactive proteins that did not enter the first-dimension gel; they serve as $M_{\mathrm{r}}$ reference points for the spots indicated by the left-hand arrowheads. The $\mathrm{P}[+++] \mathrm{mAb}(A)$ stains a spot closest to the reference spot, whereas the $\mathrm{P}[+] \mathrm{mAb}(B)$ is more basic. The $\mathrm{P}[-] \mathrm{mAb}$ stains all of the NF-H variants, including isoforms that are more basic, and migrate faster in the SDS-PAGE dimension. When the ratio of phosphorylated to nonphosphorylated NF-H is low $(D)$, this $\mathrm{P}[-] \mathrm{mAb}$ stains only the more basic forms at low apparent $M_{\mathrm{r}}$. Note the sigmoid-shaped pattern in $D$; no protein is trapped at the top of the first dimension.

that observed for the $\mathrm{P}[+++$ ] isoform (compare the arrowheads on the left for RMO24 and Ta51). Finally, a P[-] anti-NF-HmAb (RMdO9) produced a sigmoid-shaped, streaklike immunoband in the 2-dimension gel replica where NF-H isoforms migrated, characterized by fewer phosphate residues, lower $M_{\mathrm{r}}$, and a more basic isoelectric point (Fig. 6C).

The different migration patterns of these NF-H isoforms in 2-dimension gels, and in immunoblots produced with their nitrocellulose replicas, were much more obvious in immunoblots of DRGs that were generated with young compared to old rats. This is exemplified by the blot in Figure $6 D$, which contains DRG proteins from a 4-d-old rat. It was probed with the same $\mathrm{mAb}$ (RMdO9) used in Figure $6 \mathrm{C}$. Note that in younger animals, immunoreactive, nonphosphorylated isoforms of NF-H are more prominent than in adult DRGs (see also Carden et al., 1987).

$N F$ - $M$-specific $m A b s$. In a similar series of experiments using $\mathrm{mAbs}$ specific for NF-M, we also defined classes of NF-M isoforms that differed in $M_{\mathrm{r}}$ and isoelectric point depending on their extent of phosphorylation. Representative results from 1-dimension immunoblot studies are shown in Figure 5, $E-G$. For example, the NF-M isoforms detected with RMO45 (Fig. $5 E$ ) are extinguished following shorter periods of enzyme treatment than those visualized when a less phosphatase-sensitive mAb (RMO108) was applied to a similar gel replica (Fig. $5 G$ ). These immunoblots exemplify the properties of 2 different types of anti-NF-M mAbs, which recognize this polypeptide in different states of phosphorylation, $\mathrm{P}[+++](\mathrm{RMO} 45)$ and $\mathrm{P}[+]$ (RMO108). The properties of these mAbs differ substantially from those of other anti-NF-M mAbs, which recognize isoforms of this subunit regardless of phosphorylation state (Fig. $5 F, J$ ); the latter category of mAbs is regarded as phosphate-independent, or P[ind], anti-NF-M mAbs. Figure $5 J$ shows that a $\mathrm{P}$ [ind] anti-NF-M mAb can reveal at least 3 NF-M isoforms that differ in $M_{\mathrm{r}}$ (designated NF-Ma, NF-Mb, NF-Mc), even in 1-dimension blots. In contrast, $\mathrm{P}[+++] \mathrm{mAbs}$ stained only NF-Ma, while $\mathrm{P}[+] \mathrm{mAbs}$ recognized NF-Ma and NF-Mb more strongly than NF-Mc.

None of the mAbs specific for NF-M displayed properties that corresponded to the NF-H-specific $\mathrm{P}[-]$ mAbs described above. Further, all of the NF-L-specific mAbs described here (e.g., RMS21 in Fig. 5H), as well as all of the mAbs specific for bovine NF-L described earlier (Carden et al., 1985), still recognized NF-L even after extensive periods of enzymatic dephosphorylation. These $\mathrm{mAbs}$ are therefore categorized as $\mathrm{P}$ [ind] mAbs, following the rationale discussed above.

Additional studies conducted with these mAbs on replicas of 2-dimension gels assisted in the characterization of NF-M isoforms and the mAbs that detect them. Representative examples of data from these other studies are seen in Figures 7 and 8. The NF-M isoforms are seen in Figure 7, $A-D$. Four mAbs specific for peripheral NF-M determinants that differed in their phosphorylation states were used to probe the 2-dimension gel replica. Both the $\mathrm{P}[$ ind $] \mathrm{mAb}$ (Fig. $7 A$ ) and the $\mathrm{P}[+] \mathrm{mAb}$ (Fig. $7 B$ ) detected the $3 \mathrm{NF}-\mathrm{M}$ isoforms we termed NF-Ma, NF-Mb, and NF-Mc. Note that NF-Ma and NF-Mb often merge in the IEF system used here (Black et al., 1986), but that a $\mathrm{P}[++] \mathrm{mAb}$ (Fig. 7C) stains only the top 2 isoforms, whereas a $\mathrm{P}[+++]$ $\mathrm{mAb}$ (Fig. 7D) stains only NF-Ma, the most highly phosphorylated isoform of NF-M.

The existence of other NF-M isoforms is suggested by the 2-dimensional replicas, shown in Figure $7 E-G$, that were stained with the same $\mathrm{P}[$ ind $] \mathrm{mAb}$ used in Figure $7 A$. These blots show the effects of loading different amounts of NF protein on the 2-dimensional gels. At very high loads (Fig. $7 E$ ), more basic spots appear than do at low loads (Fig. $7 G$ ), an effect manifested during the first-dimension gel separation made on the basis of charge. Some of these horizontal spots also displayed size heterogeneity in the SDS-PAGE second-dimension separation, appearing at 3 levels (corersponding to NF-Ma, b, and c). Dilution of the sample beyond that shown in Figure $7 G$ diminished all 3 of these spots in concert (not shown). The presence of putative $\mathrm{NF}-\mathrm{M}$ isoforms other than NF-Ma, NF-Mb, and NF-Mc in overloaded gels suggests that the differential and progressive phosphorylation of NF-M may yield a considerable number of biochemically and immunochemically distinct variants of NF-M.

Additional spots that appear at high protein loads may repre- 


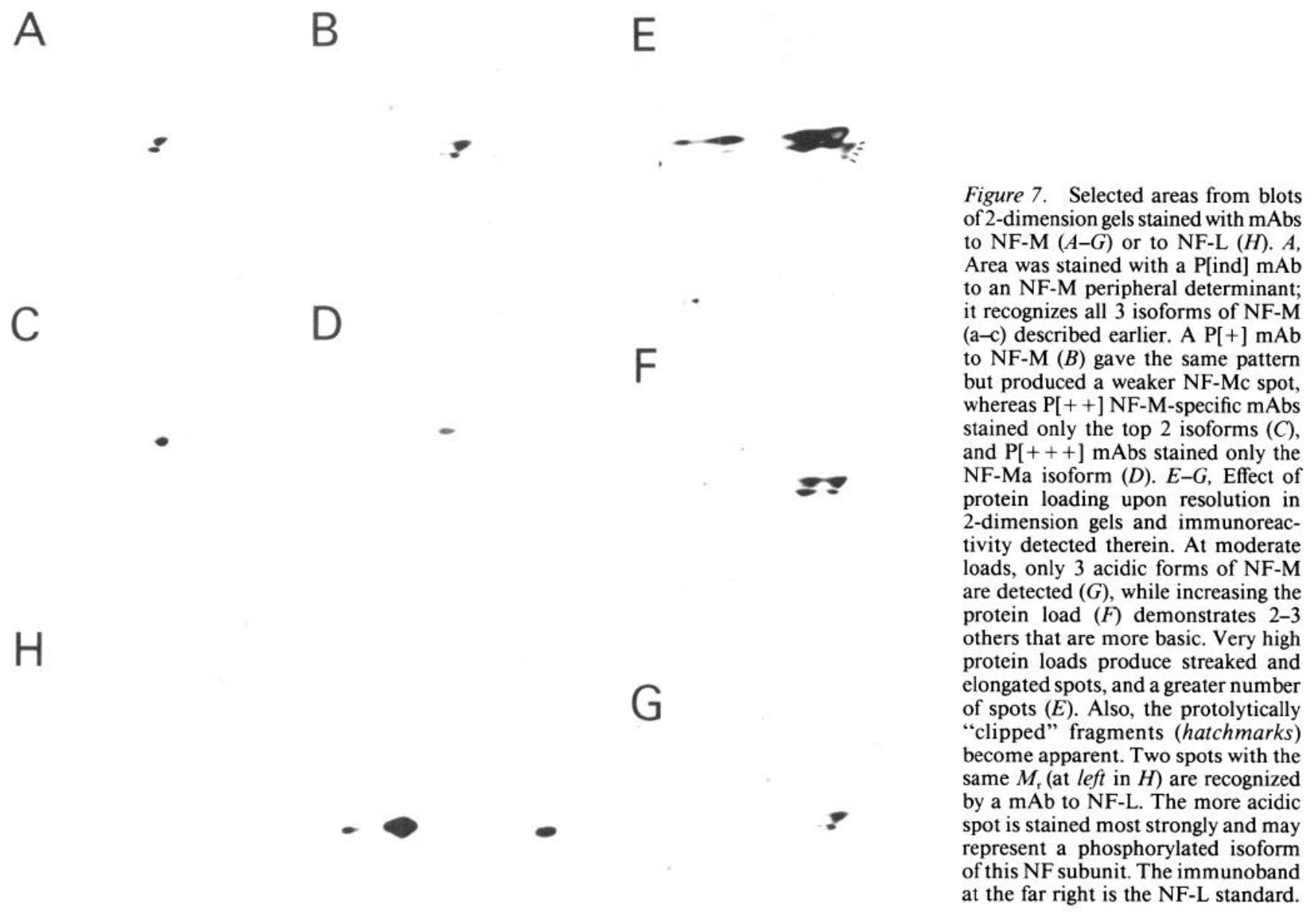

sent proteolysis. For example, Figure $7 E$ shows spots (marked by hatchmarks) that are slightly more acidic than the normal NF-Ma, b, and c spots. Additional studies conducted with a $\mathrm{P}$ [ind-core] (Fig. 8A) and a P[ind-periph] (Fig. $8 B$ ) anti-NF-M mAbs further characterize some of these proteolytic fragments. Both mAbs label similar spots that migrate to, or just ahead of, the NF-M standard. Furthermore, both mAbs recognize spots (marked by hatchmarks) that are slightly more acidic than the most strongly immunoreactive spots. These spots probably arise by proteolytic clipping of the amino terminus of NF-M, since this region is fairly basic and extremely sensitive to proteolysis (Geisler et al., 1983). Although both mAbs label similar sets of spots, as detailed above, the $\mathrm{P}$ [ind-periph] $\mathrm{mAb}$ stains a more acidic $110 \mathrm{kDa}$ fragment ( $\mathrm{P}$ in Fig. $8 B$ ), while the $\mathrm{P}$ [ind-core] mAb stains several $35-50 \mathrm{kDa}$ fragments (C, bracketed, Fig. $8 A$ ). Other $\mathrm{P}$ [ind-core] and $\mathrm{P}$ [ind-periph] anti-NF-M mAbs produced immunoblot patterns very similar to those seen in Figures $8, A$ and $B$, respectively. On the basis of their size and charge, we conclude that the low $M_{\mathrm{r}}$ spots detected by $\mathrm{P}$ [ind] mAbs, like the one shown in Figure $8 A$, correspond to the alpha-helical core fragments cleaved from NF-M near the junction of the core and peripheral domains of this subunit by chymotrypsin (see also Figs. 3, 4) and other proteases (trypsin, papain, and endoArg-C (Chin et al., 1983; M. J. Carden, unpublished observations). These fragments most likely represented endogenously derived proteolytic products, since they varied in relative amounts from experiment to experiment and were more abun- dant when proteolytic inhibitors were omitted during protein isolation.

$N F$ - $L$-specific $m A$ Abs. When mAbs specific for NF- $L$ were used to probe 2-dimension gel replicas identical to those just discussed (Fig. $7 H$ ), 2 isoelectric NF-L variants were recognized, with the same $M_{\mathrm{r}}$ as NF-L in the standard lane. The more acidic

\begin{tabular}{|c|c|}
\hline Type of $\mathrm{mAb}$ & Representative example \\
\hline \multicolumn{2}{|l|}{ NF-L } \\
\hline $\mathrm{P}$ [ind-core] & RMS21 \\
\hline \multicolumn{2}{|l|}{ NF-M } \\
\hline $\mathrm{P}[+]$ & RMO108, RMO93, RMO54 \\
\hline $\mathrm{P}[++]$ & RMO55 \\
\hline $\mathrm{P}[+++]$ & RMO45 \\
\hline $\mathrm{P}$ [ind-periph] & RMO3 \\
\hline $\mathrm{P}$ [ind-core $]$ & RMO43, RMdO10, RMO26 \\
\hline \multicolumn{2}{|l|}{ NF-H } \\
\hline $\mathrm{P}[+]$ & Ta51 \\
\hline$P[++]$ & $\mathrm{RMO} 217$ \\
\hline $\mathrm{P}[+++]$ & RMO24 \\
\hline $\mathrm{P}[-]$ & RMdO20, RMdO9, RMdT2 \\
\hline
\end{tabular}

The categories into which the mAbs were placed are summarized here and representative examples of mAbs are given. The terminology for the mAb types is defined in the text. 


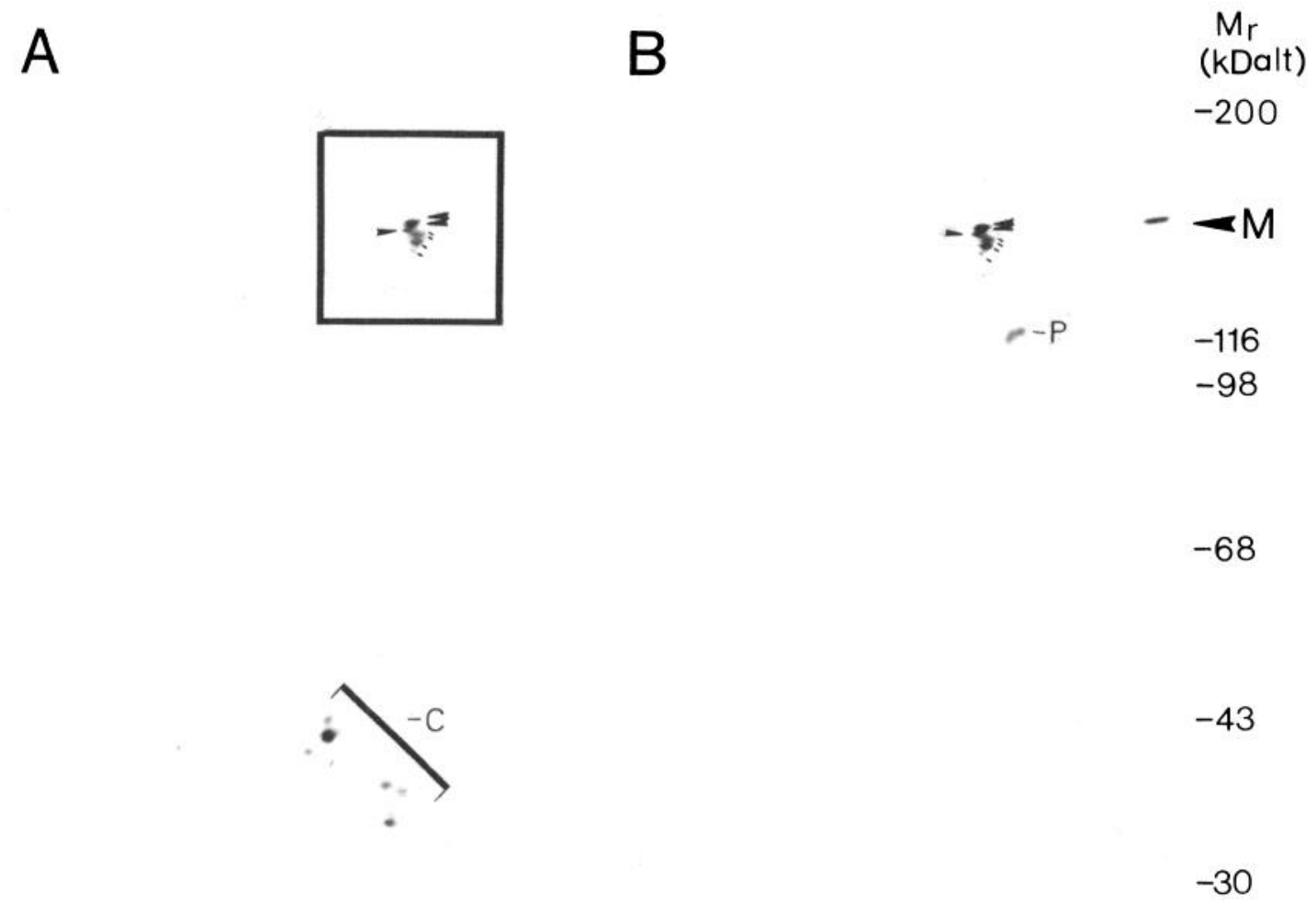

Figure 8. Immunoblots of 2-dimension gels stained with NF-M-specific mAbs. DRG proteins were separated by IEF/SDS-PAGE, electroblotted, and reacted with a $\mathrm{P}[$ ind] $\mathrm{mAb}$ to a core determinant $(A)$ or to a peripheral determinant $(B)$. The entire blot is shown in $A$ and $B$. Each mAb detects several spots (boxed in $A$ ) at the level of mature NF-M (note NF-M standard, indicated by the large arrowhead in $B$ ). Small arrowheads show the 3 spots representing the 3 NF-M isoforms we term NF-Ma, NF-Mb, and NF-Mc. Note that NF-Mc (the more basic and smaller $M_{\mathrm{r}}$ isoform) is well-resolved, but NF-Ma and b merge together. Just below these NF-M isoforms are 3-4 slightly smaller and more acidic spots (see hatchmarks), which "echo" the pattern of the NF-M isoforms, and may represent variants of NF-Ma, b, and c from which a short peptide has been removed at the $\mathrm{NH}_{2}$-terminal end (see text). Differences between the immunoblot patterns generated by the $2 \mathrm{mAbs}$ shown in $A$ and $B$ are evident. The $\mathrm{mAb}$ in $A$ stains a group of spots (bracketed, $C$ ) with $M_{\mathrm{r}}$ around $35-40 \mathrm{kDa}$. The mAb in $B$ only stains a single spot $(P)$ at $M_{\mathrm{r}}$ around $120 \mathrm{kDa}$, which is more acidic than the main NF-M spots. The extra fragments represent core $(C)$ and peripheral $(P)$ domains, respectively, generated by scission of NF-M.

isoform (middle spot, Fig. $7 H$ ) can be labeled with ${ }^{32} \mathrm{P}$ in tissue culture (V. M.-Y. Lee, unpublished observations), but the more basic form (left-hand spot, Fig. $7 H$ ) cannot and it may well correspond to the nascent form of NF-L. Note that the mAb detects both forms.

Table 2 summarizes the categories into which all of the mAbs described here can be divided, and gives representative examples of mAbs belonging to each category.

\section{Correlation of immunohistochemistry with antibody specificity}

The immunobiochemical characteristics of mAbs defined above correlated well with the different patterns of immunoreactivity we observed with these mAbs in adult rat nervous system tissues. Detailed immunohistochemical studies were conducted on sections of Bouin's fixed spinal cord and DRG, i.e., prototypical and neuroanatomically well-characterized CNS and PNS structures. For these correlative studies, we selected NF-M- and NF$\mathrm{H}$-specific $\mathrm{mAbs}$ that were representative of the $\mathrm{P}[+++], \mathrm{P}[++]$, $\mathrm{P}[+], \mathrm{P}[-]$, and $\mathrm{P}[$ ind $]$ categories described above and in Table 2. Results from these studies are illustrated in Figures 9 and 10 , and summarized in Table 3.

\section{$N F$ - $H$-specific mAbs}

Figure $9, A-D$, exemplifies the staining patterns seen in spinal cord with mAbs specific for different NF-H isoforms. In general, NF-H-specific mAbs of the $\mathrm{P}[+++], \mathrm{P}[++]$, and $\mathrm{P}[+]$ type (Fig. 9, $A-C$ ) stained spinal cord white matter (i.e., distal segments of axons) more intensely and homogeneously than spinal cord gray matter (neuronal perikarya, more proximal segments of axons and dendrites). In contrast, $\mathrm{P}[-]$ mAbs (Fig. 9D) intensely stained neuronal elements within the spinal cord gray matter, while axons within white matter were largely negative or variably immunoreactive. The $\mathrm{P}[+++]$ (Fig. $9 A$ ) and $\mathrm{P}[++]$ (Fig. $9 B$ ) mAbs yielded similar staining patterns in gray matter, but $\mathrm{P}[+] \mathrm{mAbs}$ (Fig. $9 C$ ) differed from $\mathrm{P}[+++]$ and $\mathrm{P}[++]$ $\mathrm{mAbs}$ in that they generally stained some neuronal perikarya in addition to the neurophil.

The application of increasing dilutions of $\mathrm{P}[+++], \mathrm{P}[++]$, and $\mathrm{P}[+] \mathrm{mAbs}$ rapidly extinguished any perikaryal staining produced by these antibodies in spinal cord, while axonal staining was retained. In contrast, dilution of $\mathrm{P}[-]$-type $\mathrm{mAbs}$ resulted in the extinction of axonal staining (except for that of the axons exiting the ventral horn to form the ventral roots), while 

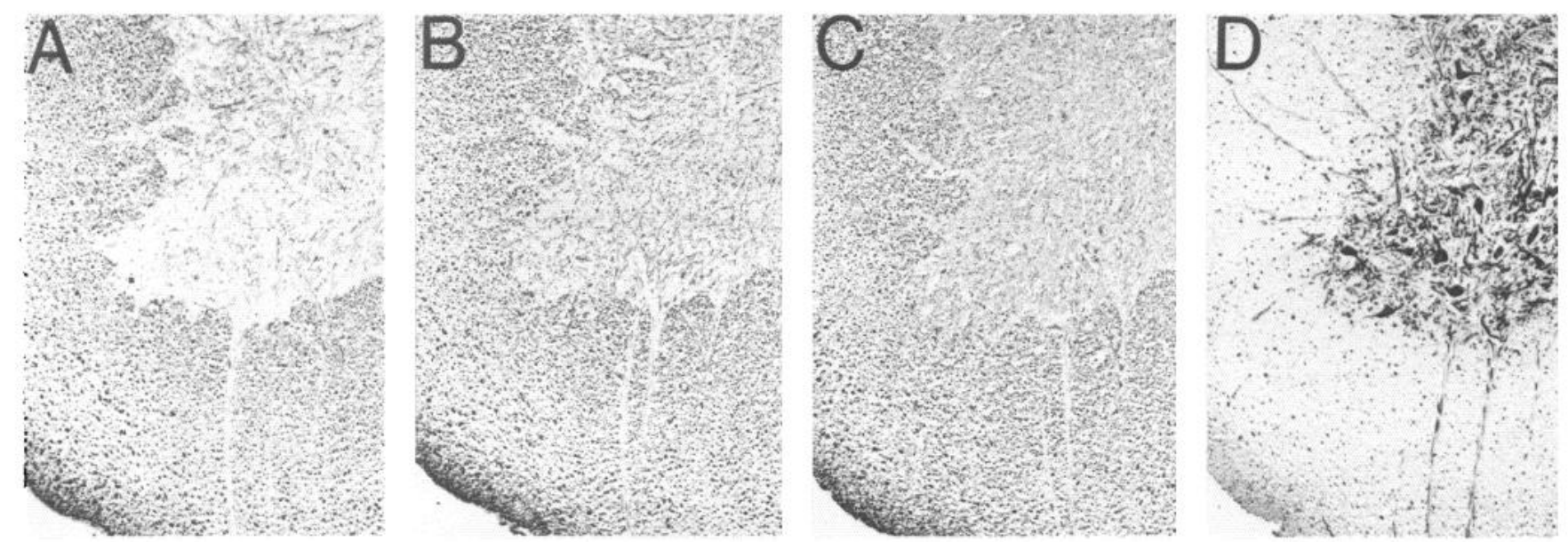

$\mathrm{RMO} 24 \quad \mathrm{P}_{+++} \mathrm{RM}$

RMO217 $P_{++}$Ta51

$\mathrm{P}+\mathrm{RMdO9}$
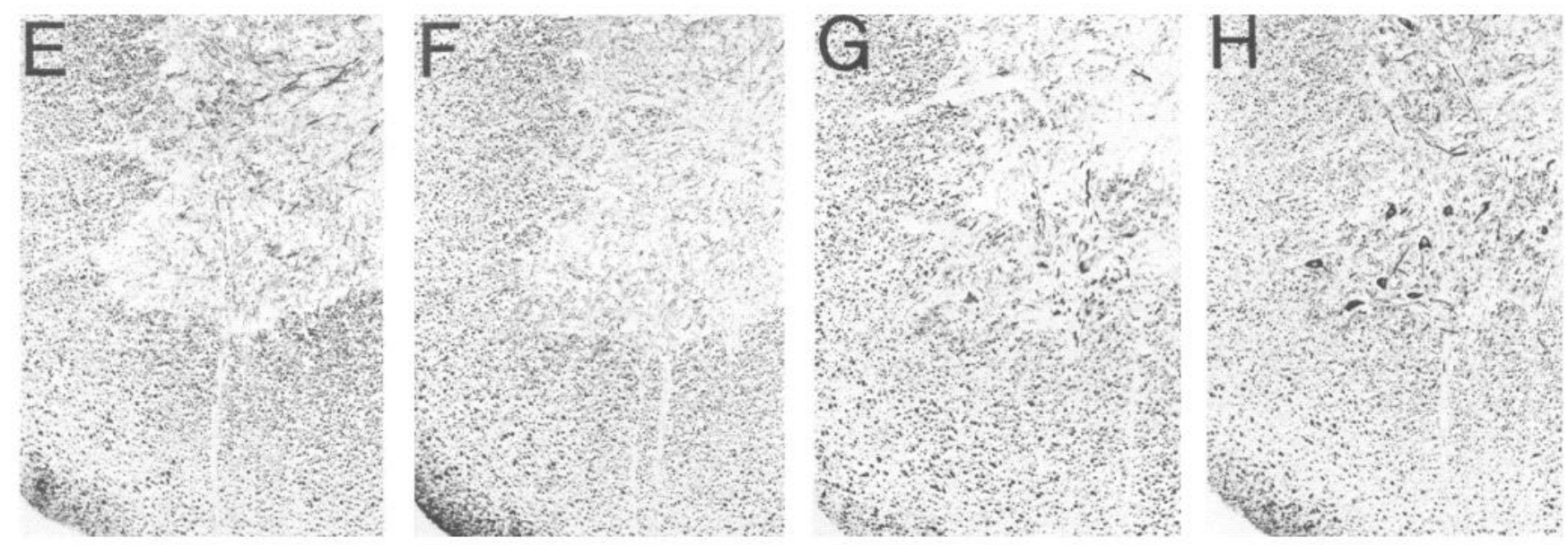

\section{$\mathrm{RMO} 45$ P+++}

RMO55 P++ RMO93

$\mathrm{P}+\mathrm{RMO3}$

$\mathrm{Pi}$
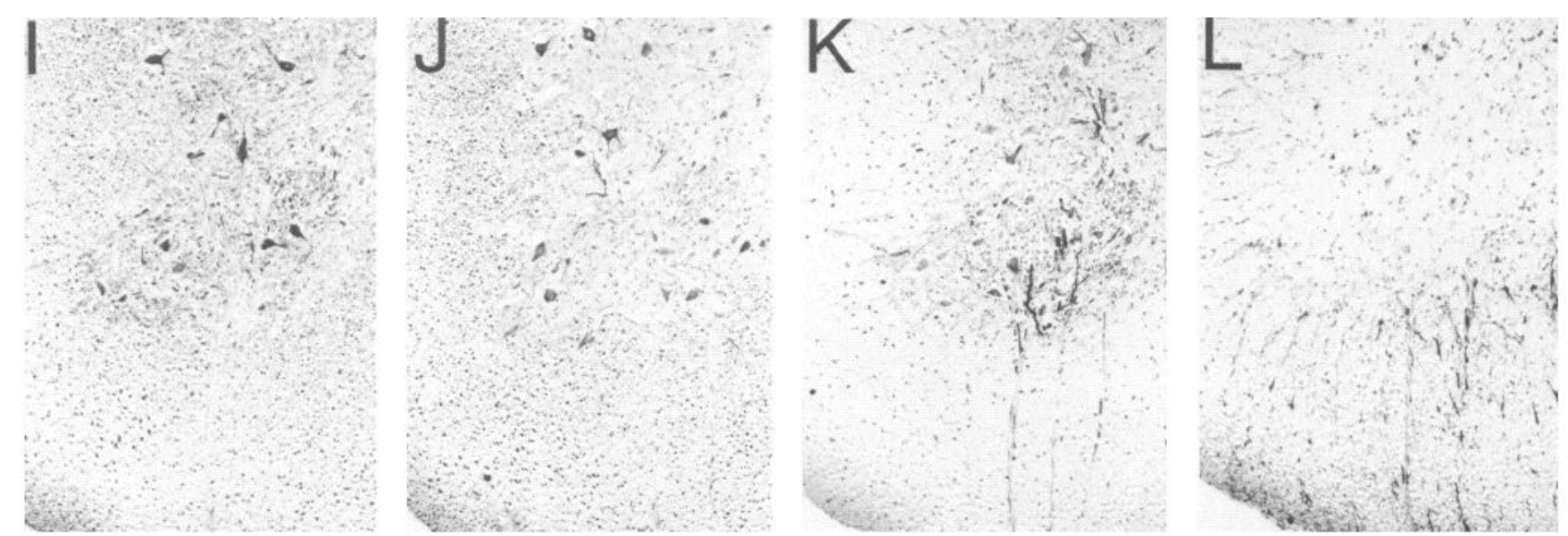

\section{RMdO10 Pi RMS12 Pi RMdO20 P- GF - control}

Figure 9. Immunohistochemical patterns derived with different mAbs applied to paraffin sections of Bouin's fixed, adult rat lumbar spinal cord. Fifty consecutive sections were cut at $6 \mu \mathrm{m}$ from the same block and stained in the same experiment. The mAbs (identified at left below each panel) were used as spent supernatants; the phosporylation state of the determinants they detect are indicated to the right below each panel. The dilutions the mAb supernatants were used at and their specificities, were as follows: $R M O 24(\mathrm{P}[+++], \mathrm{NF}-\mathrm{H})$, neat; $R M O 217(\mathrm{P}[++], \mathrm{NF}-\mathrm{H})$, neat; Ta51 $(\mathrm{P}[+], \mathrm{NF}-\mathrm{H}), \times 100 ;$ RMdO9 (P[-], NF-H) $\times 1000 ;$ RMO45 (P[+++], NF-M), neat; RMO55 (P[+++], NF-M), $\times 50 ; R M O 93$ (P[+], NF-M), $\times 1000 ; R M O 3$ (P[ind-periph], NF-M), × 100; RMdO10 (P[ind-core], NF-M), neat; RMS12 (P[ind], NF-L), neat; RMdO20 (P[-], NF-H), $\times 1000$; $G F(2.2 \mathrm{~B} 10), \times 100$. The sections were counterstained lightly with hematoxylin, and the ventral horn area (ventral surface pointing down) is shown. The width of each panel is $720 \mu \mathrm{m}$. 
Figure 10. Immunohistochemical results from adult rat DRG probed as in Figure 9 with the following mAbs: $A$, RMdO9 (P[-], NF-H), diluted $\times 10,000 ; B, \quad \mathrm{RMO} 24(\mathrm{P}[+++]$, NF-H), $\times 100 ; C$, Ta51 (P[+], NF-H, $\times 1000 ; D$, RMO93 $(\mathrm{P}[+]$, NF-M), $\times 1000 ; E, \quad \mathrm{RMdO} 10$ (P[ind-core], NF-M), neat; $F$, RMO45 $(\mathrm{P}[+++]$, $\mathrm{NF}-\mathrm{H}$, neat. The width of each panel is $1060 \mu \mathrm{m}$. The sections in $A$ and $B$ were not counterstained whereas those in $C-F$ were counterstained with hematoxylin.
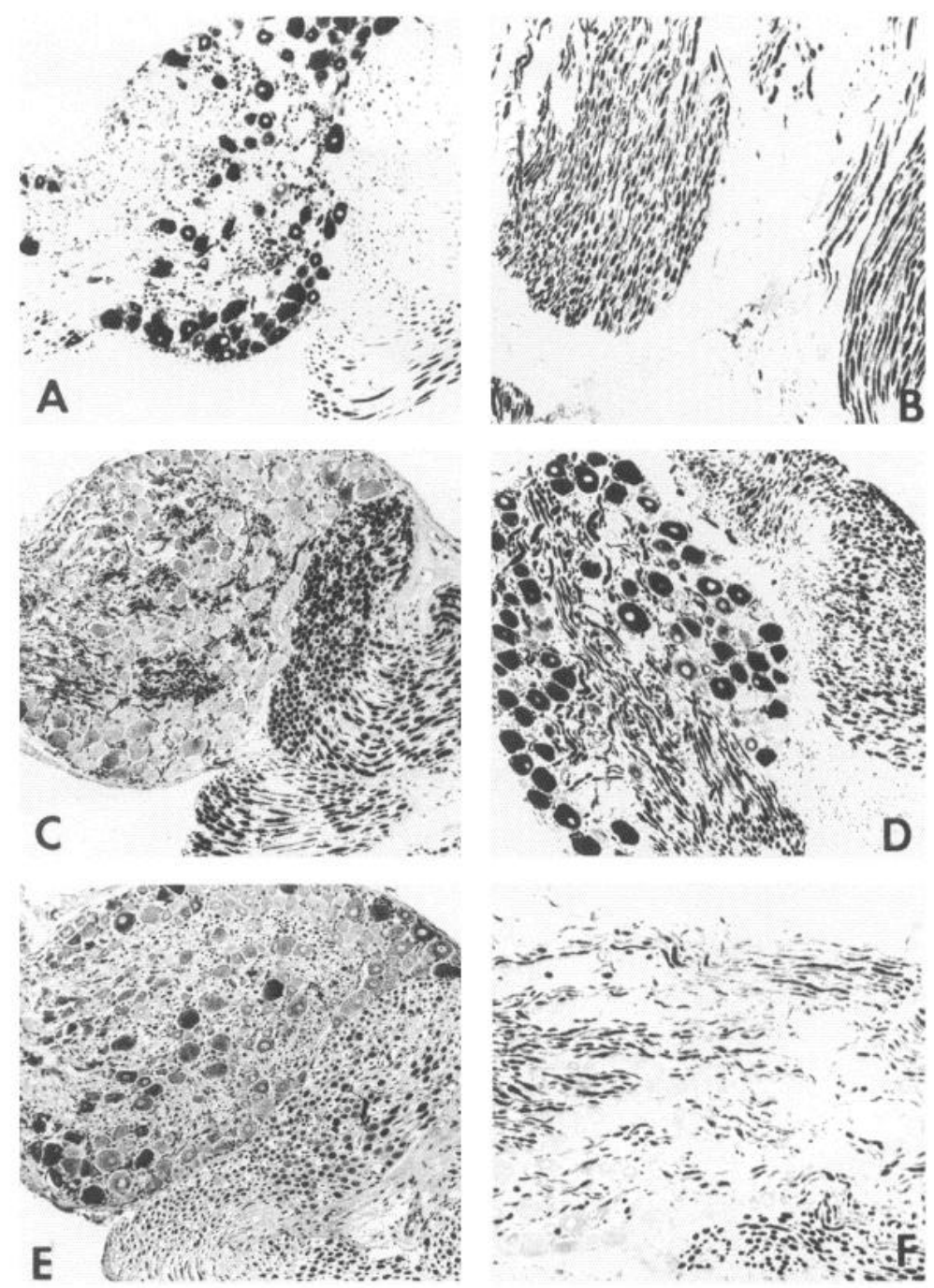

Table 3. Summary of immunohistochemical results in spinal cord and DRG

\begin{tabular}{|c|c|c|c|c|c|c|c|}
\hline \multirow[b]{2}{*}{ mAbs } & \multicolumn{2}{|c|}{$\begin{array}{l}\text { Epitope } \\
\text { location }\end{array}$} & \multicolumn{3}{|c|}{ Spinal cord } & \multicolumn{2}{|l|}{ DRG } \\
\hline & $\begin{array}{l}\text { Side- } \\
\text { arm }\end{array}$ & Core & Perikarya & Neuropil & Axons & Perikarya & Axons \\
\hline \multicolumn{8}{|l|}{ NF-M } \\
\hline $\mathrm{P}[+]$ & + & & + & ++ & +++ & +++ & +++ \\
\hline $\mathrm{P}[++]$ & + & & - & + & +++ & \pm & +++ \\
\hline $\mathrm{P}[+++]$ & + & & - & + & +++ & - & +++ \\
\hline $\mathrm{P}[$ ind $]$ & + & & ++ & ++ & ++ & ++ & ++ \\
\hline $\mathrm{P}$ [ind] & & + & ++ & + & + & ++ & + \\
\hline \multicolumn{8}{|l|}{ NF-H } \\
\hline $\mathrm{P}[+]$ & + & & + & + & +++ & + & +++ \\
\hline $\mathrm{P}[++]$ & + & & - & + & +++ & - & +++ \\
\hline $\mathrm{P}[+++]$ & + & & - & + & +++ & - & +++ \\
\hline $\mathrm{P}[-]$ & + & & +++ & ++ & + & +++ & + \\
\hline
\end{tabular}

The immunohistochemical results obtained in rat spinal cord and DRG with the different types of mAbs specific for NF-M or NF-H are presented here. The results were graded using a scale from - to +++ , reflecting negative (-) to most intense $(+++)$ immunoreactivity. The terminology for the different types of mAbs is defined in the text. 
neuronal perikarya and surrounding neurites in spinal cord gray matter were still positive. Further dilutions of $\mathrm{P}[-] \mathrm{mAbs}$ consistently diminished the staining of perikarya before the surrounding neurites lost immunoreactivity (e.g., Fig. 9K).

Nearly identical differences in immunoreactivity were observed with these mAbs (using dilute and nondilute) in sections of DRG (Fig. 10). For example, the $\mathrm{P}[-] \mathrm{mAb}$ shown in Figure $10 A$ intensely labeled neuronal perikarya and adjacent neurites, but distal axons in attached nerves (not shown) are largely negative. Almost the reverse of this pattern was seen in DRG with $\mathrm{P}[+++] \mathrm{mAbs}$ (Fig. 10B). The $\mathrm{P}[+] \mathrm{mAb}$ shown in Figure $10 \mathrm{C}$ stained proximal neurites and bundles of axons heavily, but cell bodies were variably and weakly positive. $\mathrm{P}[++] \mathrm{mAbs}$ stained DRG similarly to $P[+] \mathrm{mAbs}$, although proximal neurites were less intense than axons within the attached peripheral nerves (not shown). Since NF-H-specific mAbs generally continued to stain DRG at 2-fold higher dilutions than they did spinal cord, the concentration of NF-H may be higher in neurons of DRG than in spinal cord.

\section{$N F$ - M-specific mAbs}

The staining patterns produced by different NF-M-specific mAbs also differed in spinal cord. $\mathrm{P}[+++]$-type mAbs stained white matter axons intensely, while failing to stain perikarya (Fig. 9, $E, F$ ). Indeed, NF-II- and NF-M-specific mAbs of the $\mathrm{P}[+++]$ and $\mathrm{P}[++]$ categories yielded virtually the same immunohistochemical results in spinal cord (compare Fig. 9, $A, B, E$, and $F$ ). NF-M-specific $\mathrm{P}[+] \mathrm{mAbs}$ differed somewhat from $\mathrm{P}[+]-$ type $\mathrm{mAbs}$ specific for NF-H in that the former stained spinal cord neurons more strongly and frequently than did the latter mAbs (see Fig. 9, $G$ and $C$ ).

$\mathrm{P}$ [ind] $\mathrm{mAbs}$ specific for peripheral and core NF-M determinants (Fig. 9, $H$ and $I$, respectively) yielded spinal cord staining patterns that were similar to those seen with the anti-NF-H $\mathrm{P}[-] \mathrm{mAbs}$, although $\mathrm{P}[$ ind $] \mathrm{mAbs}$ consistently produced less immunoreactivity in spinal cord gray matter than did $\mathrm{P}[-]$ mAbs (compare Fig. 9, $D, H$, and $I$ ). P[ind] mAbs to core epitopes stained white matter much less intensely than did $P$ [ind] mAbs to peripheral epitopes (see Fig. 9, $I$ and $H$ ). These results may indicate that the NF-M isoforms detected by $\mathrm{P}$ [ind] $\mathrm{mAbs}$ more closely resemble nascent NF-M than do the isoforms detected by $\mathrm{P}[+++], \mathrm{P}[++]$, and $\mathrm{P}[+] \mathrm{mAbs}$.

NF-M-specific mAbs, like NF-H-specific mAbs, showed staining patterns in DRG (Fig. 10) that were nearly identical to those seen with the same $\mathrm{mAbs}$ in spinal cord, and they also stained perikarya more intensely in DRG than in spinal cord. However, $\mathrm{P}[+]$ NF-M mAbs stained DRG perikarya more intensely than their NF-H counterparts (compare Fig. 10, C and $D$ ), and they also stained perikarya in DRG more strongly than in spinal cord (see, for example, Figs. $10 D$ and $9 G$ ). P[ind-core] NF-M-specific mAbs stained neuronal elements in DRG and attached nerves variably and only in undiluted form (Fig. 10E).

\section{$N F$-L-specific $m A$ Abs}

Most NF-L-specific mAbs failed to stain, or only weakly stained, neuronal elements under the immunohistochemical conditions described here (e.g., Fig. 9J). P[ind] mAbs specific for NF-M core determinants behaved in a similar manner. This contrasts with the generally intense staining results achieved with mAbs specific for peripheral domain epitopes, including the $P$ [ind] $\mathrm{mAbs}$ to peripheral determinants. Core-specific mAbs may be low-affinity antibodies, since they often required higher antigen loads when used for immunoblotting than did mAbs specific for epitopes in peripheral domain sites. Nevertheless, most corespecific mAbs stained neurons intensely in acetone-fixed frozen sections of adult rat DRG by the immunofluorescence technique (see also the following paper, Carden et al., 1987). These results may be attributable to the location of epitopes recognized by these mAbs in the NF core (Trojanowski et al., 1985, 1986; Schmidt et al., 1987). Others also have noted that many mAbs to the smaller intermediate filament proteins, including NF-L, stain frozen sections best. This suggests that the core domain of these proteins is altered chemically, or otherwise structurally modified (e.g., masked), during fixation and wax embedding.

\section{Discussion}

Phosphorylation is one of the most important posttranslational modifications that NF subunits undergo; for example, it is a significant determinant of the biochemical and immunochemical properties ascribed to NF proteins, especially to NF-H and NF-M (e.g., Julien and Mushynski, 1982, 1983; Sternberger and Sternberger, 1983; Carden et al., 1985; Lee et al., 1986b; Shaw et al., 1986; Goldstein et al., 1987; Schmidt et al., 1987). Thus, it is likely that the phosphorylation state of NF-H and NF-M will be shown to mediate functional properties of these 2 subunits, and that the abnormal regulation of the kinases and phosphatases that modulate the phosphorylation of NF-H and NF-M may explain the involvement of NFs in a variety of neurodegenerative diseases (see the discussion and references in Schmidt et al., 1987). A full elucidation of the mechanisms that regulate NF protein phosphorylation is required to fully understand the functional implications of this posttranslational modification for NF-H and NF-M. To accomplish this, it will be necessary to (1) identify and charcterize the active kinases and phosphatases that control the phosphorylation state of NF proteins, and (2) precisely delineate the NF protein sequences that are the substrates for these enzymes. We have taken steps here towards the realization of these two objectives by generating a library of mAbs that recognize phosphate-dependent and independent epitopes in rat NF proteins, using these mAbs to demonstrate for the first time that a variety of distinct molecular variants of rat NF-H and NF-M exists in the normal rat nervous system, and showing that the biochemical and immunochemical properties that distinguish these NF protein variants are attributable to their phosphorylation state.

We showed previously that $\mathrm{mAbs}$ generated with NF proteins from one species cross-react variably with the same NF subunit in other species (Lee et al., 1986a). In view of this, we were required to use rat NF proteins to raise and characterize mAbs designed to probe the phosphorylation state of each NF triplet protein in this same species. Four different fusions, with different rat NF subunit proteins as immunogens, were used to prepare the library of $\mathrm{mAbs}$ described here. Notably, the specificities of the mAbs from any one fusion did not always correlate with the immunogen used to produce them. This may reflect limitations in the use of SDS-PAGE to separate some NF products, since non- and dephosphorylated NF-H both have an $M_{\mathrm{r}}$ very similar to that of NF-M.

Although the library of mAbs reported here contains the largest variety of mAbs to rat NF proteins yet described, mAbs with certain specificities were not isolated. For example, we did not obtain any $\mathrm{P}[-]$ mAbs specific only for NF-M. This may reflect the paucity of "nascent" or nonphosphorylated NF-M in situ (M. M. Black and V. M.-Y. Lee, unpublished observations), 
the difficulty in removing phosphate residues from rat NF-M, as compared to rat NF-H (Fig. 5), or the poor immunogenicity of nonphosphorylated NF-M epitopes. Also, $\mathrm{P}[+], \mathrm{P}[++]$, and $\mathrm{P}[+++] \mathrm{NF}-\mathrm{L}-$-specific mAbs were not obtained here or in previous studies using NF antigens from other species (Carden et al., 1985; Lee et al., 1986a). This probably reflects the low phosphate content of NF-L. Thus, the number of NF-L variants generated as a result of phosphorylation is probably smaller than that for NF-H and NF-M. On the other hand, some NF protein determinants appear highly immunogenic, since mAbs to them are repeatedly elicited. For example, epitopes shared by NF-M and NF-H were recognized by one-third of all $\mathrm{mAbs}$ produced using NF-M as immunogen (see also Lee et al., 1986a). This probably is due to sequence and structural homologies between highly antigenic segments of NF-H and NF-M.

The mAbs described here will permit us to identify the structural location of the epitopes they recognize, and this will prove invaluable for the characterization of the substrates on which NF protein-directed kinases and phosphatases act. For example, the majority of our $\mathrm{mAbs}$ that recognize the peripheral domain of NF-M bind to both chymotryptic fragments of NF-M $\left(M_{\mathrm{r}}\right.$ $120 \mathrm{kDa}$ and $110 \mathrm{kDa}$ ), but a single mAb, RMO54, binds only the larger $\left(M_{\mathrm{r}} 120 \mathrm{kDa}\right) \mathrm{NF}-\mathrm{M}$ fragment. This mAb may recognize a determinant at one end of the larger fragment, since removal of a small piece of the $120 \mathrm{kDa}$ protein generated the $110 \mathrm{kDa}$ product, which was never recognized by this mAb. Further, RMO54 is a $\mathrm{P}[+]$-type mAb, but generally $\mathrm{P}[+]$-type anti-NF-M mAbs recognize both chymotryptic fragments of NF-M. This leads us to speculate that other, distinct NF isoforms, perhaps resulting from the highly orchestrated phosphorylation and dephosphorylation of a number of different regions within the peripheral domain of NF-H and NF-M, may be present within each of the phosphorylation-dependent categories that we have established here.

It is therefore quite likely that the data reported here for these mAbs underestimate the number of naturally occurring phosphate-dependent variants of NF subunits. This may account for the appearance in the 2-dimension immunoblots of more basic spots with the same $M_{\mathrm{r}}$ at high than at low protein loading (Fig. $7, E-G$ ), and for our classification of NF-M into only 3 phosphate categories, while Julian and Mushynski (1983) showed that there are approximately 9 phosphate sites on rat NF-M. Accordingly, the $\mathrm{P}[+], \mathrm{P}[++]$, and $\mathrm{P}[+++]$ definitions used here must be considered as nonquantitative indications of phosphate content.

The biochemical importance of these different forms of NF-M and NF-H was firmly established by their different migration patterns in 2-dimension immunoblots. While the broad categories of different states of phosphorylation of NF-M can be resolved into discrete spots, NF-H variants always form a sigmoid-shaped immunoband. This peculiar profile is probably due to the large number of highly charged phosphate residues variably situated within the C-terminal domain of NF-H, and to limitations in available 2-dimension gel systems for the separation of the many phosphorylated isoforms of NF-H that undoubtedly are present along the sigmoid-shaped NF-H immunoband.

The NF-M and NF-H variants described here are not solely in vitro phenomena, since the distinct staining patterns obtained using $\mathrm{P}[-]-, \mathrm{P}[$ ind $]-, \mathrm{P}[+]-, \mathrm{P}[++]-$, and $\mathrm{P}[+++]$-type mAbs specific for either NF-H or NF-M provide strong evidence for the in vivo existence of these different classes of NF-H and NF-M isoform. The data also suggest that there is an orderly progression of phosphorylation of NF-H and NF-M following their synthesis in perikarya, subsequent assembly into filaments, and transport along axons. Earlier studies implied a somatofugal gradient of NF protein phosphorylation (Sternberger and Sternberger, 1983; Bennett and DiLullo, 1985; Lee et al., 1986b; Trojanowski et al., 1986; Schmidt et al., 1987). However, since the antibodies used in earlier studies were either more limited in number and specificity or not characterized in the manner described here, it was not possible to establish a close correlation between the differential phosphorylation of NF-H and NF-M and the location of the phosphorylated variants of these subunits in tissues. Indeed, this paper describes for the first time mAbs that can distinguish rat NF-M in different states of phosphorylation.

Since we were able to identify a number of progressively phosphorylated isoforms of NF-M and NF-H, and to show that phosphorylation normally occurs to a variable extent in different parts of the neuron, we would emend some previous statements about the location of NF phosphorylation. For example, our results with $\mathrm{P}[+++] \mathrm{mAbs}$ agree with those reported by Sternberger and Sternberger (1983), but we now can show that $\mathrm{P}[+]$ NF-H and NF-M isoforms are present in cell bodies, and that they become increasingly more prevalent along axons. The observation that the perikaryal staining by $\mathrm{P}[+] \mathrm{mAbs}$ diminished upon dilution of these $\mathrm{mAbs}$ without loss of axonal staining suggests that the quantity of $\mathrm{P}[+]$ epitopes is lower in perikarya than in axons.

Although our immunochemical data confirm the work of Julien and Mushynski (1983), who localized the phosphorylated sites of NF-H and NF-M to the COOH-terminal peripheral domain of each of these subunits, we cannot precisely identify these sites, state their exact location within the peripheral domain, or indicate the sequence in which the major isoforms identified here are phosphorylated. However, since $\mathrm{P}[+] \mathrm{mAbs}$ recognized all of the same isoforms as $\mathrm{P}[+++] \mathrm{mAbs}$ on immunoblots, in addition to the less phosphorylated ones, we speculate that $\mathrm{P}[+++]$ variants arise following the formation of $\mathrm{P}[+]$ variants. This is consistent with at least two interpretations of the immunohistochemical data obtained with $\mathrm{P}[+]$ versus $\mathrm{P}[+++] \mathrm{mAbs}$. First, the $\mathrm{P}[+++] \mathrm{NF}$ isoforms may be generated by an axon-restricted kinase that further phosphorylates the $\mathrm{P}[+]$ isoforms produced by the action of another kinase present in both perikarya and axons. If NF-H and NF-M require different kinases, it is possible that at least 4 different enzymes are involved in this process. Alternatively, the restriction of $\mathrm{P}[+++]$ isoforms to the axonal region of a neuron could be related to the transport of NFs. NF proteins are transported slowly from the cell body, at a rate around $1-5 \mathrm{~mm} / \mathrm{d}$ in adult rats (Hoffman and Lasek, 1975). Thus, a single kinase that migrates with NFs during their transport might produce $\mathrm{P}[+] \mathrm{ep}$ itopes in the perikaryon, while further phosphorylation of NFs by the same kinase to $\mathrm{P}[+++]$ forms could occur later in the axon because of slow kinetics of this enzyme or, more likely, differential activation of the kinase in the axonal versus the perikaryal milieu.

Other observations concerning the phosphorylation of NF proteins provide tentative support for the latter speculations: (1) Bovine NFs incubated with ${ }^{32} \mathrm{P}$-ATP in vitro incorporate much more radioactivity overnight than after $30 \mathrm{~min}$ (M. J. Carden, unpublished observations); (2) the metabolic labeling of NFs in cultured neurons occurs slowly over days, rather than 
hours (Bennett and DiLullo, 1985; Black et al., 1986); (3) in pathological conditions associated with the accumulation of NFs in perikarya, such as nerve transection, aluminum intoxication, and Alzheimer's disease (see Traub, 1985; Goldstein et al., 1987; and Schmidt et al., 1987, for references), phosphorylated isoforms of NF-H and/or NF-M are detected at much higher levels than in controls. In fact, Goldstein et al. (1987) have shown that the $\mathrm{P}[+++]$ isoforms are the most prominent ones that accumulate in perikarya following nerve transection. It is not known whether the lack of movement by NFs allows this increased phosphorylation to occur, or whether abnormal phosphorylation disrupts the normal processes of axonal transport. However, it should be noted that when NF transport is blocked in IDPN neuropathy, there is no increase in the phosphorylation of NF proteins (M. J. Carden et al., unpublished observations).

Although these and other important questions concerning the functional and structural importance of NF subunit phosphorylation remain unanswered at this time, it is clear that our approach to the elucidation of the biochemical and immunological properties of NF-H and NF-M isoforms has the potential to provide tools to address these questions. The library of mAbs described here contains powerful molecular probes with which to initiate these inquiries. In the following report (Carden et al., 1987), we use these $\mathrm{mAbs}$ to probe in detail the developmental expression of different classes of $\mathrm{NF}$ isoforms in the rat.

\section{References}

Bennett, G. S., and C. DiLullo (1985) Slow posttranslational modification of a neurofilament protein. J. Cell Biol. 100: 1799-1804.

Black, M. M., P. Keyser, and E. Sobel (1986) Interval between the synthesis and assembly of cytoskeletal proteins in cultured neurons. J. Neurosci. 6: 1004-1012.

Carden, M. J., and P. A. M. Eagles (1983) Neurofilaments from ox spinal nerves. Isolation, disassembly, reassembly and cross-linking properties. Biochem. J. 215: 227-237.

Carden, M. J., W. W. Schlaepfer, and V. M.-Y. Lee (1985) The structure, biochemical properties and immunogenicity of neurofilament peripheral regions are determined by phosphorylation. J. Bio. Chem. 260:9805-9817.

Carden, M. J., J. Q. Trojanowski, W. W. Schlaepfer, and V. M.-Y. Lee (1987) Two-stage expression of neurofilament polypeptides during rat neurogenesis with carly establishment of adult phosphorylation patterns. J. Neurosci. 7: 3489-3504.

Chin, T. K., P. A. M. Eagles, and A. Maggs (1983) The proteolytic digestion of ox neurofilaments with trypsin and alpha-chymotrypsin. Biochem. J. 215: 239-252.

Czosnek, H., D. Soifer, and H. M. Wisniewski (1980) Studies on the biosynthesis of neurofilament proteins. J. Cell Biol. 85: 726-734.

Geisler, N., E. Kaufman, S. Fischer, U. Plessmann, and K. Weber (1983) Neurofilament architecture combines structural principles of intermediate filaments with carobxy-terminal extensions increasing in size between triplet proteins. EMBO J. 2: 1295-1302.

Geisler, N., S. Fischer, J. Vanderkerckhove, J. Van Damme, U. Plessmann, and K. Weber (1985) Protein-chemical characterization of $\mathrm{NF}-\mathrm{H}$, the largest mammalian neurofilament component; intermediate filament-type sequences followed by a unique carboxy-terminal extension. EMBO J. 4: 57-63.

Georges, E., S. Lefebre, and W. E. Mushynski (1986) Dephosphorylation of neurofilaments by exogenous phosphatases has no effect on reassembly of subunits. J. Neurochem. 47: 477-483.

Glicksman, M. A., and M. Willard (1985) Differential expression of the three neurofilament polypeptides. Ann. NY Acad. Sci. 455: 479491.

Goldstein, M. E., L. A. Sternberger, and N. H. Sternberger (1983) Microheterogeneity ("neurotypy") of neurofilament proteins. Proc. Natl. Acad. Sci. USA 80: 3101-3105.

Goldstein, M. E., H. Cooper, J. Bruce, M. J. Carden, V. M.-Y. Lee, and W. W. Schlaepfer (1987) Alterations in the phosphorylation of neu- rofilament proteins following transection of rat sciatic nerve and chromatolysis. J. Neurosci. 7: 1586-1594.

Hickey, W. F., V. M.-Y. Lee, J. Q. Trojanowski, L. J. McMillan, T. J. McKearn, J. Gonatas, and N. K. Gonatas (1983) Immunohistochemical applications of monoclonal antibodies against myelin basic protein and neurofilament triplet proteins: Advantages over antisera and technical limitations. J. Histochem. Cytochem. 31: 1126-1135.

Hoffman, P. N., and R. J. Lasek (1975) The slow component of axonal transport: Identification of major structural polypeptides of the axon and their generality among mammalian neurons. J. Cell Biol. 66: $351-366$.

Julien, J. P., and W. E. Mushynski (1982) Multiple phosphorylation sites in mammalian neurofilament polypeptides. J. Biol. Chem. 257: 10467-10470.

Julien, J. P., and W. E. Mushynski (1983) The distribution of phosphorylation sites among identified proteolytic fragments of mammalian neurofilaments. J. Biol. Chem. 258: 4019-4025.

Kaspi, C., and W. E. Mushynski (1985) Characterization of interspecies size heterogeneity of the large subunit of mammalian neurofilaments. Ann. NY Acad. Sci. 455: 794-796.

Ksiezak-Reding, H., and S.-H. Yen (1986) Human and bovine neurofilament proteins contain different amounts of phosphate and form a blue complex with the carbocyanine dye "stains-all." J. Cell Biol. 103: 421a.

Lee, V. M.-Y., H.-L. Wu, and W. W. Schlaepfer (1982) Monoclonal antibodies recognize individual neurofilament triplet proteins. Proc. Natl. Acad. Sci. USA 79: 6089-6092.

Lee, V. M.-Y., C. D. Page, H.-L. Wu, and W. W. Schlaepfer (1984) Monoclonal antibodies to gel excised glial filament protein and their reactivity with other intermediate filament proteins. J. Neurochem. 42: $25-32$.

Lee, V. M.-Y., M. J. Carden, and W. W. Schlaepfer (1986a) Structural similarities and differences between neurofilament proteins from five different species as revealed using monoclonal antibodies. J. Neurosci. 6: $2179-2186$.

Lee, V. M.-Y., M. J. Carden, and J. Q. Trojanowski (1986b) Novel monoclonal antibodies provide evidence for the in situ existence of a nonphosphorylated form of the largest neurofilament subunit. J. Neurosci. 6: 850-858.

Lewis, S. A., and N. J. Cowan (1985) Genetics, evolution, and expression of the $68,000 \mathrm{~mol}$. wt. neurofilament protein: Isolation of a cloned cDNA probe. J. Cell Biol. 100: 843-850.

Lewis, S. A., and N. J. Cowan (1986) Anomalous placement of introns in a member of the intermediate filament multigene family: An cvolutionary conundrum. Mol. Cell. Biol. 6: 1529-1534.

Liem, R. K. H., S.-H. Yen, G. E. Solomon, and M. L. Shelanski (1978) Intermediale filaments in nervous tissues. J. Cell Biol. 79: 637-645.

Myers, M. W., R. A. Lazzarini, V. M.-Y. Lee, W. W. Schlaepfer, and D. L. Nelson (1987) The human mid-size neurofilament subunit: A repeated protein sequence and the relationship of its gene to the intermediate filament gene family. EMBO J. 6: 1617-1626.

Pruss, R. M., R. Mirsky, M. Raff, R. Thorpe, A. J. Dowding, and B. Anderton (1981) All classes of intermediate filaments share a common antigenic determinant defined by a monoclonal antibody. Cell 27: 419-428.

Schlaepfer, W. W., and L. A. Freeman (1978) Neurofilament proteins of rat peripheral nerve and spinal cord. J. Cell Biol. 78: 653-662.

Schlaepfer, W. W., C. Lee, J. Q. Trojanowski, and V. M.-Y. Lee (1984) Persistence of immunoreactive neurofilament proteins breakdown products in transected rat sciatic nerve. J. Neurochem. 43: 857-864.

Schmidt, M. L., M. J. Carden, V. M.-Y. Lee, and J. Q. Trojanowski (1987) Phosphate dependent and independent neurofilament epitopes in the axonal swellings of patients with motor neuron disease and controls. Lab. Invest. 56: 282-294.

Shaw, G., M. Osborn, and K. Weber (1986) Reactivity of a panel of neurofilament antibodies on phosphorylated and dephosphorylated neurofilaments. Eur. J. Cell Biol. 42: 1-9.

Steinert, P. M., A. C. Steven, and D. R. Roop (1985) The molecular biology of intermediate filaments. Cell 42: $411-419$.

Sternberger, L. A., and N. H. Sternberger (1983) Monoclonal antibodies distinguish phosphorylated and nonphosphorylated forms of neurofilaments in situ. Proc. Natl. Acad. Sci. USA 80: 6126-6130.

Traub, P. (1985) Intermediate Filaments: A Review, Springer-Verlag, Berlin.

Traub, P., G. Perides, H. Schimmel, and A. Scherbarth (1986) Inter- 
action in vitro of nonepithelial intermediate filament proteins with total cellular lipids, individual phospholipids, and a phospholipid mixture. J. Biol. Chem. 26: 10558-10568.

Trojanowski, J. Q., M. A. Obrocka, and V. M.-Y. Lee (1985) Distribution of bovine neurofilament subunits in neurons and neuronal processes: Immunohistochemical studies of bovine cerebellum with subunit specific monoclonal antibodies. J. Histochem. Cytochem. 33: $557-563$.

Trojawnoswki, J. Q, N. Walkenstein, and V. M.-Y. Lee (1986) Expression of neurofilament subunits in neurons of the central and peripheral nervous system: An immunohistochemical study with monoclonal antibodies. J. Neurosci. 6: 650-660. 